\title{
APLICAÇÃO DE UMA ABORDAGEM INTERACTIVA BASEADA EM PONTOS DE REFERÊNCIA A UM PROBLEMA MULTIOBJECTIVO DE LOCALIZAÇÃO- TRANSPORTE
}

\author{
Maria João Alves ${ }^{1}$ \\ João Clímaco
}

\begin{abstract}
Resumo: Este artigo apresenta resultados de uma pesquisa interactiva de soluções eficientes num problema multicritério de localização-transporte. É utilizado um procedimento interactivo de pesquisa direccional que foi desenvolvido para problemas genéricos de programação linear inteira e inteira-mista multiobjectivo [1]. O problema de localização-transporte em estudo consiste em seleccionar locais para abrir estações de tratamento de resíduos tóxicos e determinar os trajectos e quantidades de material a transportar desde as fontes de resíduo até às estações de tratamento. Este modelo foi proposto por Coutinho-Rodrigues et al. [3(b), 4] e instâncias do modelo foram já estudadas usando um sistema de apoio à decisão desenvolvido pelos mesmos autores [3,4].
\end{abstract}

Palavras-chave: multiobjectivo, transporte, localização.

Abstract:

Keywords:

\section{INTRODUÇÃO}

Este trabalho pretende mostrar a aplicação de um procedimento de pesquisa interactiva de soluções eficientes a um problema multicritério de localização-transporte. A abordagem interactiva proposta [1] assenta no uso de pontos de referência para efectuar pesquisas direccionais e destina-se a problemas de programação linear inteira e inteira-mista multiobjectivo. Esta abordagem combina estratégias multicritério baseadas em pontos de referência - em particular, a métrica de
Tchebycheff - com técnicas de branchand-bound.

Assumindo um protocolo simples de interacção com o agente de decisão (AD), em cada fase de diálogo o AD apenas deve especificar um novo ponto de referência ou indicar uma função objectivo (critério) que pretende melhorar relativamente à solução eficiente anterior. É neste último caso que se desencadeia uma pesquisa direccional, havendo lugar a um "varrimento" de soluções eficientes ao longo de uma direcção particular. Esta direcção assegura o melhoramento do critério escolhido pelo AD.

\footnotetext{
${ }^{1}$ Faculdade de Economia, Universidade de Coimbra / INESC Coimbra, PORTUGAL, mjoao@inescc.pt
} 
Cada solução eficiente (não dominada) é obtida pela optimização de um problema escalarizante que projecta um ponto de referência do espaço dos critérios no conjunto das soluções não dominadas. $\mathrm{O}$ problema escalarizante usado nesta abordagem é o seguinte:

$$
\begin{gathered}
\mathrm{P}\left(\underline{\mathrm{z}}^{+}\right) \min \quad \alpha-\rho \sum_{\mathrm{i}=1}^{\mathrm{k}} \underline{\mathrm{c}}^{\mathrm{i}} \underline{\mathrm{x}} \\
\text { s.a: } \quad \underline{\mathrm{c}}^{\mathrm{i}} \underline{\mathrm{x}}+\alpha \geq \mathrm{z}_{\mathrm{i}}^{+} \quad \mathrm{i}=1, \ldots, \mathrm{k} \\
\mathrm{A} \underline{\mathrm{x}}=\underline{\mathrm{b}} \quad \underline{\mathrm{x}} \geq \underline{0}
\end{gathered}
$$

em que $A \underline{x}=\underline{b}$ representa as restrições funcionais do problema, $\mathrm{k}$ é o número de funções objectivo e $\underline{\mathrm{i}}$ é o gradiente da função objectivo i. Assume-se que todas as funções objectivo são a maximizar. A função objectivo i é, assim, definida por “max $z_{i}=\underline{c} \underline{\underline{i}} \underline{x}$. O ponto de referência é $\underline{\mathrm{z}}^{+}=\left(\mathrm{z}_{1}^{+}, \ldots, \mathrm{z}_{\mathrm{k}}^{+}\right)$. Se $\underline{\mathrm{z}}^{+}$for superior a todos os pontos dos critérios admissíveis, então este programa determina a solução cujo ponto dos critérios $\underline{\mathrm{z}}=\left(\underline{\mathrm{c}^{3}} \underline{\mathrm{x}}, \ldots, \underline{\mathrm{c}}^{\mathrm{k}} \underline{\mathrm{x}}\right)$ minimiza a distância (aumentada) de Tchebycheff a $\underline{z}^{+}$. A variável $\alpha$ dá o valor dessa distância. Mas $\alpha$ nem sempre representa uma distância e, por isso, não pode ter restrição de sinal, porque se o ponto de referência for atingível, então $\mathrm{P}\left(\underline{\mathrm{z}}^{+}\right)$já não representa a minimização de uma distância. O termo $-\rho \sum_{i=1}^{k} \underline{c}^{i} \underline{x}$, em que $\rho$ é uma constante positiva pequena, perturba a métrica de Tchebycheff para uma métrica aumentada. Esta perturbação garante que qualquer solução óptima de $\mathrm{P}\left(\underline{\mathrm{z}}^{+}\right)$é eficiente do problema multiobjectivo. Note-se que, na ausência deste termo, poder-se-iam encontrar soluções que são apenas fracamente eficientes.

Se o AD escolher um critério, seja $z_{j}$, que pretende melhorar relativamente ao valor da solução eficiente anterior (pesquisa direccional), o procedimento actualiza automaticamente o ponto de referência $\underline{z}^{+}$ incrementando (ou decrementando, se $z_{j}$ for a minimizar) $z_{j}^{+}$e mantendo as outras componentes iguais. A variação de $z_{j}^{+}$é determinada por uma fase de análise de sensibilidade/pós-optimização. Como se pode observar em $\mathrm{P}\left(\underline{z}^{+}\right)$, as componentes de $\underline{z}^{+}$são os termos independentes das $\mathrm{k}$ primeiras restrições do problema escalarizante. A fase de pós-optimização analisa, então, a variação do termo independente de uma restrição de $\mathrm{P}\left(\underline{\mathrm{z}}^{+}\right)$. Trata-se de um processo iterativo que utiliza e compara informação proveniente dos nós terminais da árvore de branchand-bound correspondente à solução óptima de $\mathrm{P}\left(\underline{z}^{+}\right)$para analisar os efeitos da variação de $z_{j}^{+}$. O incremento de $z_{j}^{+}$ faz-se de modo a assegurar que a solução eficiente seguinte seja próxima mas diferente da anterior. Em problemas multiobjectivo de programação inteiramista existem soluções contínuas que podem ser conhecidas através de variações muito pequenas de $\underline{z}^{+}$. Mas, ao longo de uma mesma direcção de pesquisa, podem ser necessárias grandes variações de $\underline{z}^{+}$para poder "escapar” da solução anterior e "saltar" uma descontinuidade nas soluções eficientes. A pesquisa direccional é, assim, um processo de varrimento de soluções ao longo de uma dada direcção, produzindo soluções contínuas (a menos de um passo controlado pelo $\mathrm{AD}$ ) enquanto tal for possível, e saltando automaticamente as descontinuidades, quando tal for imperativo.

A informação proveniente da árvore de branch-and-bound anterior permite, não só a análise de sensibilidade que altera o ponto de referência, como também constitui o ponto de partida para o cálculo da solução eficiente seguinte. Assim, para resolver $\mathrm{P}\left(\underline{z}^{+}\right)$com $\underline{\mathrm{z}}^{+}$modificado, o procedimento começa por actualizar alguma informação que foi preservada nos nós terminais da árvore de branchand-bound anterior e, se necessário, procede depois a novas ramificações para atingir novamente o óptimo. Com o intuito de não ter uma árvore cada vez maior, o que acarretaria dificuldades de manuseamento e de espaço, tenta-se simplificá-la antes de proceder a novas 
ramificações. A simplificação consiste em cortar ramos que eliminam partes da árvore. Os cortes da árvore relacionam-se com a existência de limitações de variáveis (do tipo $x_{i} \leq K_{i}$ ou $x_{i} \geq K_{i}+1$ ) que deixaram de estar activas no novo problema escalarizante. Esta forma de aproveitar a árvore de branch-and-bound anterior para os cálculos seguintes permite diminuir os tempos computacionais, em muitos casos de forma significativa, resultando pesquisas mais rápidas. Para mais detalhes sobre esta abordagem interactiva, veja-se [1].

Esta abordagem interactiva foi aplicada a um problema de localização-transporte formulado segundo um modelo multiobjectivo de programação linear inteira-mista. O problema consiste em seleccionar um sub-conjunto de locais, de entre um conjunto pré-definido, para abrir estações de tratamento de resíduos tóxicos e estabelecer as rotas de transporte dos materiais (e respectivas quantidades) desde os locais geradores até às estações de tratamento.

A minimização do custo deve, obviamente, ser considerada neste tipo de decisões. Mas, dado o perigo envolvido no transporte e tratamento de materiais tóxicos, a minimização do risco e a sua distribuição espacial (equidade na distribuição) têm também um papel muito importante [5]. Current e Ratick [5] propuseram um modelo multicritério para este tipo de problemas. O modelo considera 5 funções objectivo que, como os autores referem, estão, em geral, em conflito: "por exemplo, uma solução que minimiza o custo irá enviar grandes quantidades de materiais através de vias de menor custo; isto levará a que as populações ao longo dessas vias fiquem expostas a elevados riscos; por outro lado, optimizar o critério da equidade do transporte conduz a que pequenas quantidades sejam transportadas por um elevado número de vias o que tende a incrementar o custo e o risco total envolvido, mas reduz a exposição máxima a que um indivíduo está sujeito”.
O modelo proposto em [5] considera, por uma questão de facilidade, que os materiais não podem ser transportados através de locais geradores ou locais potenciais para as estações de tratamento. Esta opção no sentido de simplificar o problema, poder-se-ia, contudo, justificar em certos casos por questões de segurança. Baseando-se neste modelo, Coutinho-Rodrigues et al. propõem um outro [3(b), 4] que ultrapassa esta questão sem ter necessidade de modificar a rede que representa espacialmente o problema. $E$ É este o modelo que adoptamos neste trabalho.

Os problemas de localização-transporte que envolvem materiais perigosos deparam-se, em geral, com três tipos de dificuldades [3]. São problemas inteiros ou inteiros-mistos muitas vezes difíceis de resolver, mesmo em casos monocritério. Por outro lado, o número de soluções eficientes pode crescer exponencialmente com o tamanho do problema. E, por último, quando o número de funções objectivo aumenta, a análise de compromissos entre as várias alternativas (soluções) torna-se cada vez mais difícil.

Coutinho-Rodrigues et al. [3, 4] desenvolveram um sistema de apoio à decisão interactivo dedicado a este tipo de problemas. As soluções eficientes são geradas usando o método dos pesos (optimização de somas pesadas das funções objectivo), podendo incluir-se restrições nos valores das funções objectivo. A consideração destas restrições adicionais permite alcançar soluções eficientes não suportadas. As soluções são calculadas usando 'sofware standard' de optimização de problemas de programação linear inteira-mista. Segundo os autores, a apresentação das soluções são os “olhos” do sistema. É usada uma técnica de representação gráfica designada por BAGAL ('Best Againt Least'). Nesse gráfico, cada solução é representada sob a forma de teia-de-aranha podendo ser facilmente comparada com a solução ideal e a anti- 
ideal - soluções que definem os contornos interno e externo do BAGAL.

Neste trabalho propomos uma nova abordagem para o problema. O processo de cálculo de soluções eficientes, já referido atrás, baseia-se no uso pontos de referência o que permite alcançar qualquer solução eficiente, incluindo as não suportadas.

A instância do problema que estudaremos a seguir usa dados inspirados num problema real. Os dados foram-nos facultados pelos autores do modelo, e correspondem à rede estudada em [4] (em [3] foi estudado um problema simplificado deste).

\section{FORMULAÇÃO DO PROBLEMA}

Seja $\mathrm{G}=(\mathrm{N}, \mathrm{A})$ uma rede composta por um conjunto de nós $\mathrm{N}$ e um conjunto A de arcos dirigidos $(i, j)$ que ligam o nó $i$ ao nó $j$. Seja $\mathrm{N}=(\mathrm{F}, \mathrm{W}, \mathrm{T})$ em que $\mathrm{F}$ é o conjunto de estações de tratamento potenciais, W é o conjunto de fontes de resíduo/material tóxico e $\mathrm{T}=\mathrm{N} \backslash\{\mathrm{F} \cup \mathrm{W}\}$ é o conjunto dos outros nós (nós de transporte) que são apenas pontos de passagem. Considerem-se ainda as seguintes definições:

$X_{i j}$ - (variável) quantidade de resíduo enviada do nó $i$ para o nó $j$.

$Y_{j}$ - (variável binária) $Y_{j}=1$ se a estação de tratamento $j \in \mathrm{F}$ é aberta e $Y_{j}=0$ no caso contrário.

$w_{i}$ - quantidade de resíduo gerada em $i \in \mathrm{W}$ num dado período de tempo.

$a_{i j}$ - população total a menos de uma distância D do arco $(i, j)$

$a_{j}$ - factor de densidade populacional junto ao local da estação $j \in \mathrm{F}$

$c_{i j}$ - custo, por unidade de resíduo, de atravessar o arco $(i, j)$

$f_{j}$ - custo fixo de abrir a estação $j \in \mathrm{F}$

$h_{j}$ - custo de operação, por unidade de resíduo, da estação $j \in \mathrm{F}$

$k_{j}$ - capacidade máxima da estação $j \in \mathrm{F}$
A formulação do problema é a seguinte:

$$
\begin{aligned}
\min \quad \mathrm{Z}_{1}=\sum_{i} \sum_{j} a_{i j} X_{i j} \\
\min \quad \mathrm{Z}_{2}=\sum_{j \in F} a_{j}\left(\sum_{i} X_{i j}-\sum_{i} X_{j i}\right) \\
\min \quad \mathrm{Z}_{3}=M \\
\min \quad \mathrm{Z}_{4}=P \\
\min \quad \mathrm{Z}_{5}= \\
\sum_{i} \sum_{j} c_{i j} X_{i j}+\sum_{j \in F}\left(f_{j} Y_{j}+h_{j}\left(\sum_{i} X_{i j}-\sum_{i} X_{j i}\right)\right)
\end{aligned}
$$

Sujeito a:

$$
\begin{aligned}
& \sum_{j} X_{i j}-\sum_{j} X_{j i}=w_{i} \\
& \forall i \in \mathrm{W} \\
& \sum_{i} X_{i j}-\sum_{i} X_{j i} \leq k_{j} Y_{j} \\
& \forall j \in \mathrm{F} \\
& \sum_{i} X_{i l}-\sum_{i} X_{l i}=0 \\
& \forall l \in \mathrm{T} \\
& \sum_{i} X_{i j}-\sum_{i} X_{j i} \geq 0 \\
& \forall j \in \mathrm{F} \\
& \sum_{i} X_{i l} \leq \mathrm{M} \\
& \forall l \in \mathrm{T} \\
& \quad X_{i j} \leq M \\
& \forall(i, j) \text { com } i \text { e } j \in \mathrm{W} \cup \mathrm{F} \\
& \sum_{i} X_{i j}-\sum_{i} X_{j i} \leq P \\
& \forall j \in \mathrm{F} \\
& X_{i j} \geq 0 \\
& \forall(i, j) \in \mathrm{A} \\
& Y_{j} \in\{0,1\} \\
& \forall j \in \mathrm{F}
\end{aligned}
$$

O conjunto de restrições (1) assegura que todo o resíduo gerado é enviado das fontes para outros nós; (2) proíbe que seja retido resíduo numa estação se ela não for aberta (i.e. $Y_{j}=0$ ) e, caso seja aberta, restringe a retenção de resíduo à sua capacidade máxima; (3) são equações de equilíbrio que impõem que todos os nós de transporte (T), que não são nem fontes nem estações de tratamento, funcionem 
apenas como nós de passagem; (4) complementa (2) para estabelecer as condições de equilíbrio nos nós de estações potenciais quando estes funcionam apenas como pontos de passagem (i.e., estações fechadas). As restrições (5) e (6) definem o valor da variável $M$ que representa o máximo risco a que um indivíduo fica exposto devido ao transporte de resíduo. Este índice de risco é quantificado pela maior quantidade de resíduo que atravessa algum nó de passagem (T) ou uma ligação directa entre uma fonte (W) e uma estação (F). O conjunto de restrições (7) define o valor da variável $P$ que representa o máximo risco a que um indivíduo fica exposto devido ao processamento nas estações. Este índice de risco é quantificado pela maior quantidade de resíduo que é processado em alguma estação. (8) assegura o transporte de quantidades não-negativas (não necessariamente inteiras) e (9) estabelece a natureza binária das decisões de localização.

As funções objectivo $Z_{1}$ e $Z_{2}$ são critérios de minimização de risco em que $Z_{1}$ representa o risco total do transporte e $\mathrm{Z}_{2}$ o risco total do processamento nas estações. As funções objectivo $Z_{3}$ e $Z_{4}$ representam critérios de equidade em que se minimiza a máxima exposição a que um indivíduo está sujeito devido ao transporte de resíduo $\left(\mathrm{Z}_{3}\right)$ e devido ao processamento nas estações $\left(Z_{4}\right)$. A função objectivo $Z_{5}$ minimiza 0 custo total que inclui os custos de transporte e custos de operação do sistema, fixos e variáveis.

A instância do problema em estudo considera uma rede com 50 nós, em que 4 são estações de tratamento, 15 são fontes de resíduos tóxicos e 31 são nós de transporte. A rede tem 113 arcos não dirigidos que podem ser atravessados em ambos os sentidos, o que corresponde a 226 arcos dirigidos. Na formulação, este problema assume 232 variáveis: 226 variáveis $X_{i j}$, 4 variáveis binárias $Y_{j}$, e as variáveis auxiliares $M$ e $P$. Há 107

ENGEVISTA, v. 7, n. 1, p. 32-54, abril 2005 restrições (excluindo as de nãonegatividade): 15 restrições do tipo (1), 4 do tipo (2), 31 do tipo (3), 4 do tipo (4), 31 do tipo (5), 18 do tipo (6) e 4 do tipo (7).

Para maior clareza de notação, na secção seguinte utilizaremos $F_{j}$ para designar $j \in \mathrm{F}$ e, analogamente, $\mathrm{W}_{i}$ e $\mathrm{T}_{l}$ para $i \in \mathrm{W}$ e $l \in \mathrm{T}$, respectivamente.

\section{APLICAÇÃO DO SISTEMA DE APOIO À DECISÃO AO PROBLEMA DE LOCALIZAÇÃO-TRANSPORTE}

\subsection{BREVE DESCRIÇÃO DO SISTEMA}

A abordagem interactiva baseada em pontos de referência [1], cujas características principais foram apresentadas na secção 1, está integrada num sistema computacional desenvolvido em DELPHI para ambiente Windows. O sistema inclui um editor de problemas em formato de "folha de cálculo", procedimentos de cálculo e meios gráficos de interacção com o $\mathrm{AD}$ e apresentação de resultados. Uma descrição deste sistema encontra-se em [2].

A pesquisa interactiva baseada em pontos de referência constitui o módulo principal do sistema. O diálogo com o AD assenta na especificação de níveis de aspiração para os critérios (pontos de referência) ou indicação do critério que o $\mathrm{AD}$ pretende melhorar relativamente a uma solução prévia - pesquisa direccional. Como complemento desta informação, o AD pode ainda impor limites nos valores dos critérios. São restrições adicionais que garantem que as soluções eficientes obtidas durante uma pesquisa direccional são progressivamente melhores no critério escolhido sem que nunca sejam piores que determinados níveis noutros critérios. Contudo, o AD pode desejar adquirir um conhecimento inicial mais global acerca do problema antes de proceder a pesquisas mais focadas como as pesquisas direccionais. Para tal, o AD 
pode requerer o cálculo das soluções eficientes que optimizam individualmente cada uma das funções objectivo (que compõem a tabela de "pay-off" e definem a solução ideal) e/ou algumas soluções eficientes dispersas obtidas a partir de somas pesadas das funções objectivo. Todos os resultados que o AD considere interessantes podem ser guardados na memória do sistema (e/ou em disco) para avaliação e comparação posterior.

O sistema inclui diferentes meios gráficos e numéricos de apresentação de resultados. Os valores das funções objectivo das soluções eficientes calculadas podem ser visualizados sob vários formatos gráficos - barras, pontos ou linhas - e sob a forma numérica, com opções de ordenação. A apresentação habitual dos valores das variáveis é a numérica. O sistema inclui ainda uma representação em rede para problemas com estruturas de rede semelhantes àquela que abordamos neste trabalho. Em problemas inteiros puros bi-critério ou tri-critério (que não é o caso aqui tratado), o espaço dos pontos de referência é também apresentado graficamente. Trata-se da representação de regiões (áreas) de pontos de referência que conduzem à mesma solução eficiente. Esta decomposição em regiões de indiferença dá indicações ao $\mathrm{AD}$ de conjuntos de pontos de referência que conduzem a soluções eficientes já conhecidas, pelo que a sua exploração é desnecessária.

Ao longo do estudo do problema serão descritas, com maior detalhe, algumas das características gráficas e de interacção com o AD.

\subsection{ESTUDO DO PROBLEMA E ILUSTRAÇÃO DO FUNCIONAMENTO DO SISTEMA}

Nesta secção iremos apresentar resultados da aplicação do sistema de apoio à decisão ao problema de localização-transporte. A pesquisa interactiva de soluções eficientes tentará ilustrar o funcionamento do sistema em geral, e do algoritmo de pesquisa direccional em particular. Será feita uma análise de cada uma das soluções eficientes obtidas para o problema.

Iniciámos o processo de pesquisa com o cálculo das 5 soluções eficientes que minimizam individualmente cada uma das funções objectivo. Dado que estas soluções nos dão um conhecimento geral de estratégias de decisão extremas, faremos uma análise mais detalhada destas soluções. Elas dão-nos uma percepção inicial das gamas de valores dos critérios, informação importante para que o AD possa identificar mais tarde soluções de compromisso.

As características destas soluções são as seguintes.

\begin{tabular}{lccccc}
\hline & $Z_{1}(\min )$ & $Z_{2}(\min )$ & $Z_{3}(\min )$ & $Z_{4}(\min )$ & $Z_{5}(\min )$ \\
\hline Solução 1 & $\mathbf{1 4 6 7 2 1 0}$ & 25955000 & 8040 & 15630 & 3701069 \\
Solução 2 & 2939590 & $\mathbf{1 5 5 9 2 5 0 0}$ & 14460 & 34650 & 3223059 \\
Solução 3 & 3799851 & 21770318 & $\mathbf{1 6 8 2 . 7}$ & 13462 & 3579522 \\
Solução 4 & 2137958 & 23388750 & 6370 & $\mathbf{8 6 6 2 . 5}$ & 3367100 \\
Solução 5 & 3324450 & 23677500 & 9410 & 25410 & $\mathbf{2 5 9 7 ~ 1 6 6}$ \\
\hline
\end{tabular}

Solução 1 - solução eficiente que minimiza $\mathrm{Z}_{1}$ (risco total do transporte).

A solução que minimiza o risco total do transporte considera a abertura de todas as estações de tratamento. Isso acarreta um elevado risco total nas estações $\left(Z_{2}\right)$ e um custo também muito elevado

ENGEVISTA, v. 7, n. 1, p. 32-54, abril 2005 (relembre-se os custos fixos para abertura de todas as estações). As maiores exposições individuais ao resíduo (riscos individuais $Z_{3}$ e $Z_{4}$ ) são moderados. Este plano contempla uma rede pouco "densa" em termos de utilização de vias de transporte (veja-se a fig. 1). As estações $F_{1}, \quad F_{2}, \quad F_{3}$ e $F_{4}$ processam, 
respectivamente, 640, 5780, 15630 e 12600 unidades. Note-se que a estação com maior processamento é $F_{3}$ $\left(15630=Z_{4}\right)$ que é também aquela que se situa no local com maior população - daí que $Z_{2}$ seja elevado. A maior exposição individual durante o transporte $\left(Z_{3}\right)$ é 8040 dada pela ligação $W_{2}-F_{4}$.

A fig. 1 é cópia da janela do sistema que mostra as características da rede da solução. As vias de comunicação usadas estão a traço mais grosso com indicação do respectivo sentido. As estações de tratamento ('FAC') fechadas têm o formato $\square$ e as abertas (que nesta solução são todas) têm formato $\square$. Na figura, os nós fontes de resíduos tóxicos são designados por 'WASTE' e os nós de transporte por 'TN'. Durante a utilização do sistema, o analista pode visualizar, para cada nó, o total de resíduo que entra $(+)$, o que sai (-) e a respectiva diferença $(+/-)$. Esta característica é visível na fig. 1
- posicionando o cursor num qualquer nó, neste caso o nó 'FAC' 2, a barra de estado (no fundo na janela) mostra a respectiva informação.

Repare-se na fig. 1 que todo o resíduo gerado em $W_{12}$ (880) é enviado pelo percurso $W_{12}-T_{11}-F_{3}$ quando existe uma via de ligação directa $W_{12}-F_{3}$. Apesar de contra-intuitivo, este facto é explicado pela existência de elevada população $\left(a_{i j}\right)$ em $W_{12}-F_{3} \quad$ o que condiciona exclusivamente a $1^{\text {a }}$ função objectivo, aquela que se pretende minimizar nesta solução. A população em $W_{12}-F_{3}$ é representada pelo coeficiente 70 enquanto que em $W_{12}-T_{11}-F_{3}$ é de apenas 17 o que diminui $Z_{1}$ em 46640 face à hipótese $W_{12}-F_{3}$. Contudo, o percurso adoptado sacrifica o custo em 31116.8 face a $W_{12}-F_{3}$.

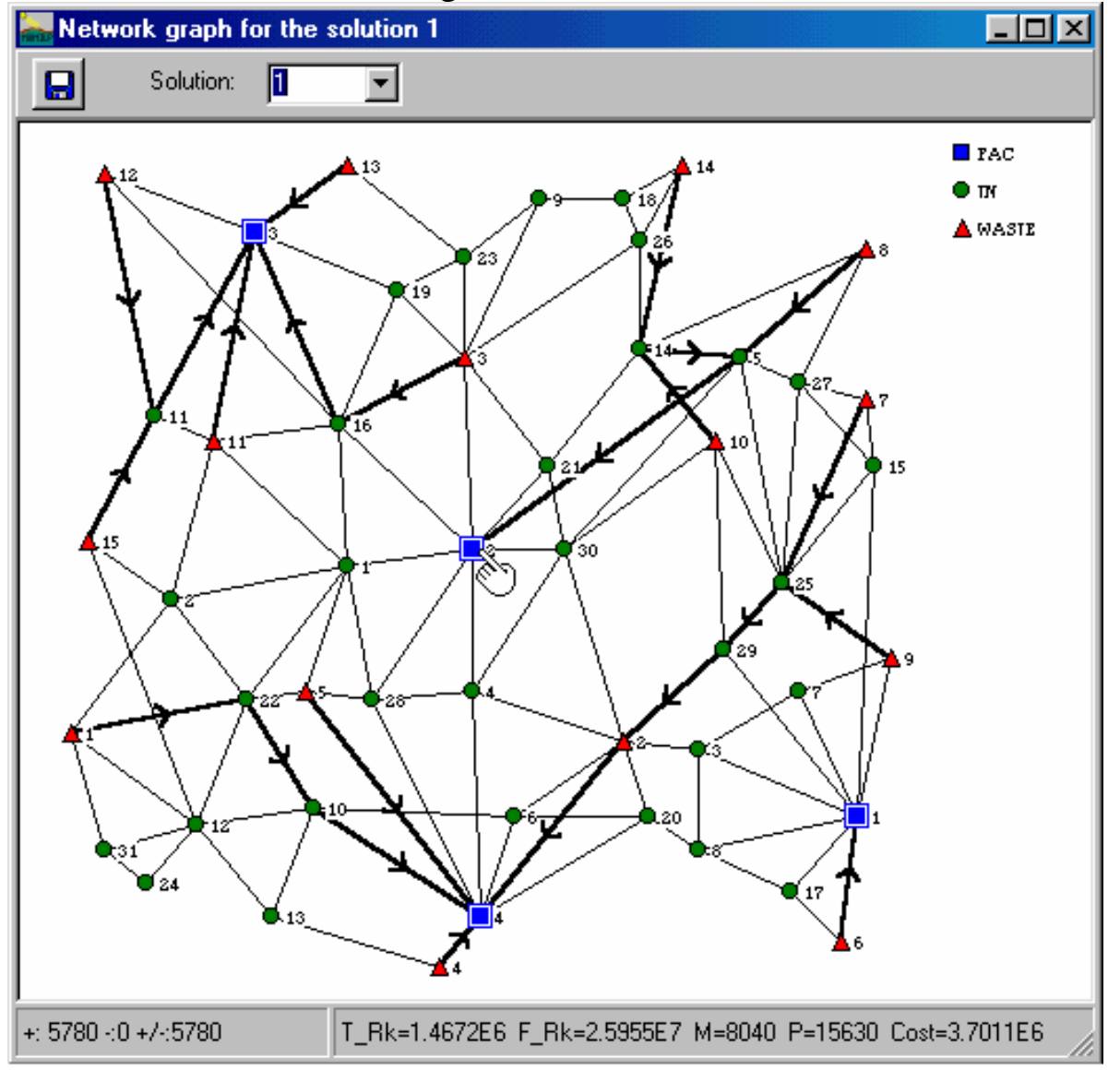

Fig. 1 - Rede da solução 1. 
Solução 2 - solução eficiente que minimiza $Z_{2}$ (risco total nas estações de tratamento).

Em contraste com a solução 1, esta solução considera a abertura de apenas uma estação de tratamento, $F_{4}$, que é a que se situa no local com menos população, pelo que minimiza o risco total nas estações $\left(Z_{2}\right)$. Contudo, como é a única estação, os riscos individuais são muito elevados. Note-se que o valor de $\mathrm{Z}_{4}$ (maior exposição nalguma estação) é máximo (34650) dado que todo o resíduo é processado na mesma estação. Há, assim, um grande desequilíbrio entre as populações sujeitas a risco. A população de $F_{4}$, apesar de pouca, é muito sacrificada. O custo total é menor do que na solução 1. A maior exposição individual durante o transporte $\left(Z_{3}\right)$ é 14460 dada pela ligação $W_{2}-F_{4}$. Nesta via passa o resíduo proveniente de 7 fontes, quase metade do total das fontes, o que representa cerca de $40 \%$ do total do resíduo. A fig. 2 apresenta as características espaciais desta solução.

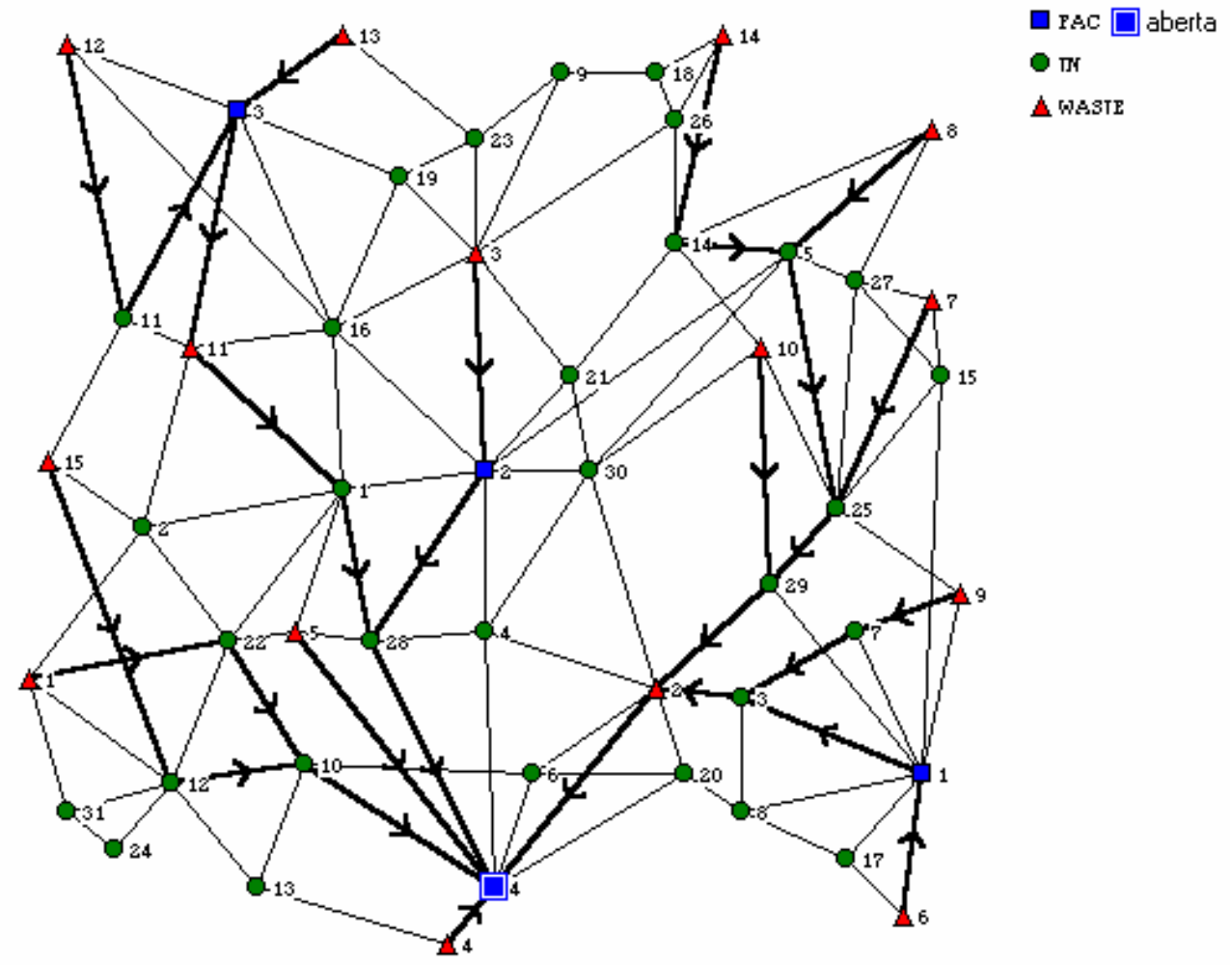

Fig. 2 - Rede da solução 2.

$\underline{\text { Solução } 3}$ - solução eficiente que minimiza $Z_{3}$ (maior exposição individual durante o transporte).

Tal como na solução 1 , também esta solução considera a abertura de todas as estações de tratamento, só que, neste caso, a rede de utilização de vias de transporte é muito "densa” (veja-se a fig. 3 ). As vias e nós de passagem são muitos, mas são atravessados por baixas quantidades de resíduo - a maior é
1682.7 e atravessa 70\% dos nós de transporte activos (que, por sua vez, são $84 \%$ do número total dos nós de passagem ' $T N$ ') e atravessa também todas as ligações $W-F$ excepto $W_{12}-F_{3}$. A maior quantidade processada $\left(Z_{4}\right)$ é 13462 em $F_{4}$ e a menor é 5252 em $F_{2}$ (para além do processamento, este nó funciona também como ponto de passagem). O custo total é elevado. 


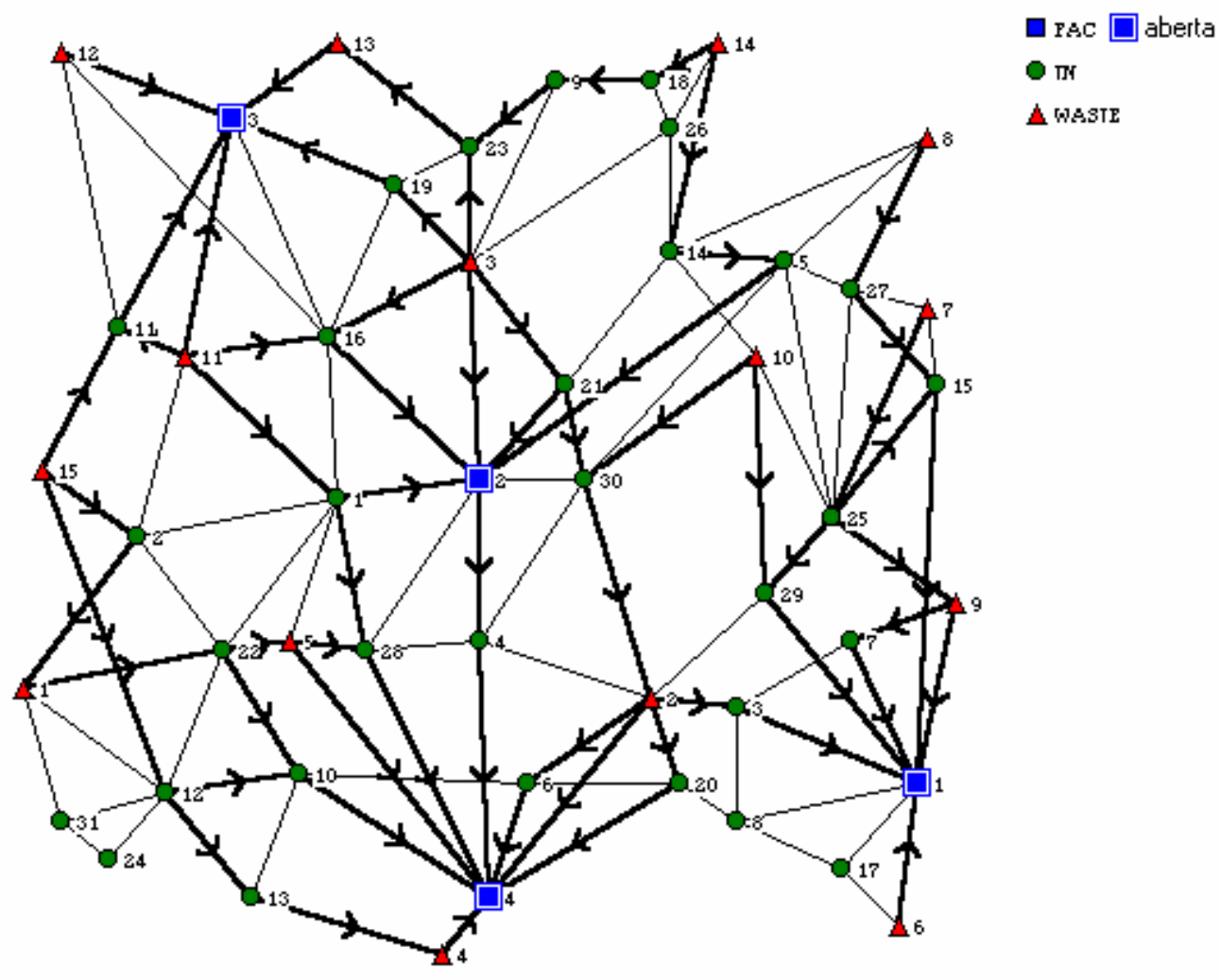

Fig. 3 - Rede da solução 3.

Solução 4 - solução eficiente que minimiza $Z_{4}$ (maior exposição individual devido ao processamento nas estações).

Tal como nas soluções 1 e 3, também esta solução considera a abertura de todas as estações de tratamento (veja-se a fig. 4). Como $\mathrm{Z}_{4}$ visa a minimização da maior quantidade processada, a quantidade total de resíduo é dividida em partes exactamente iguais (8662.5) pelas 4 estações. Resultam valores relativamente elevados para o risco total das populações nas estações $\left(Z_{2}\right)$ e custo total $\left(Z_{5}\right)$. A maior exposição durante o transporte $\left(Z_{3}\right)$ é 6370 e refere-se à ligação $W_{3}-F_{2}$.
Observa-se na rede da fig. 4 que, tal como na solução 1 , o resíduo de $W_{12}$ é enviado primeiro para $T_{11}$ e deste para $F_{3}$ quando existe uma ligação directa $W_{12}-$ $F_{3}$. Com esta configuração privilegia-se $\mathrm{Z}_{1}$ em detrimento de $\mathrm{Z}_{5}$ (custo) porque estas vias são menos populosas, mas têm custos de transporte mais elevados. A solução que apenas difere desta na utilização de $W_{12}-F_{3}$, em vez de $W_{12}-T_{11}-$ $F_{3}$, é também eficiente e óptima alternativa para $\mathrm{Z}_{4}$. Os valores de $\mathrm{Z}_{2}, \mathrm{Z}_{3}$ e $\mathrm{Z}_{4}$ nessa solução são iguais aos da solução 4, e $Z_{1}=2$ 184598, $Z_{5}=335983$. 


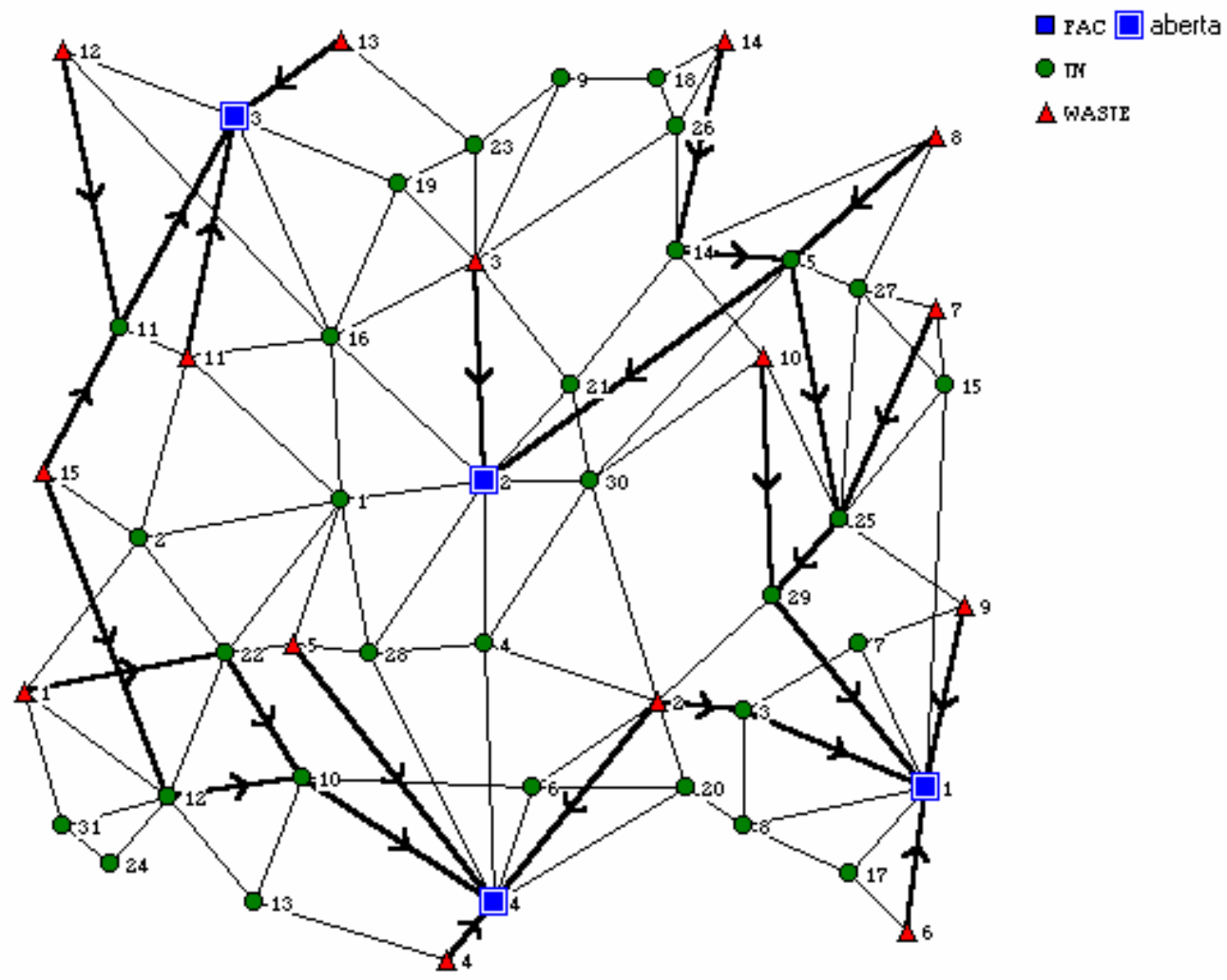

Fig. 4 - Rede da solução 4.

Solução 5 - solução eficiente que minimiza $Z_{5}$ (custo total).

O menor custo total é conseguido pela abertura de 2 estações de tratamento, $F_{1}$ e $F_{2}$ (fig. 5). Ressalta que, embora $F_{4}$ apresente os menores custos de abertura e de operação, ela não é aberta. Todas as outras funções objectivo têm valores relativamente elevados. Contudo, nenhuma delas atinge o máximo. A maior quantidade processada $\left(Z_{4}\right)$ é 25410 em $F_{2}$. A estação $F_{1}$ processa 9240 unidades. A maior exposição durante o transporte $\left(Z_{3}\right)$ é 9410 na ligação $W_{3}-F_{2}$. 


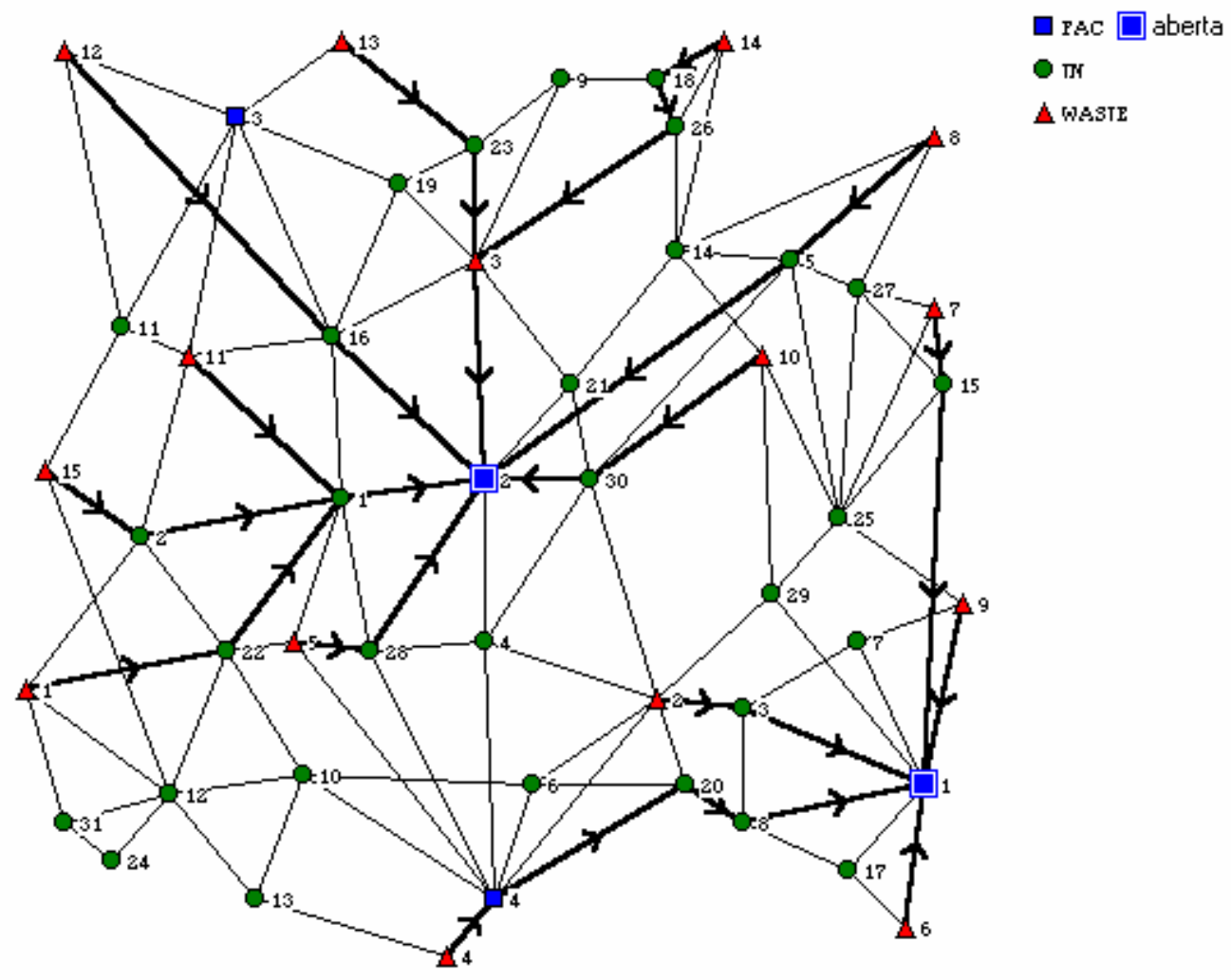

Fig. 5 - Rede da solução 5.

Conhecidas as 5 primeiras soluções, decidiu-se então calcular a solução eficiente que minimiza a distância de Tchebycheff $\left(\mathrm{L}_{\infty}\right)$ ao ponto ideal $\underline{\mathrm{Z}}^{*}=(1467210, \quad 15592500, \quad 1682.7$,

\begin{tabular}{|c|c|c|c|c|c|}
\hline & $Z_{1}(\min )$ & $Z_{2}(\min )$ & $Z_{3}(\min )$ & $Z_{4}(\min )$ & $Z_{5}(\min )$ \\
\hline Solução 6 & 2536719 & 16662009 & 24275 & 31085 & 3666675 \\
\hline
\end{tabular}

É uma solução relativamente desequilibrada nos valores das funções objectivo: $Z_{1}$ é moderado e $Z_{2}$ bastante baixo, mas o valor de $Z_{3}$ é o maior encontrado até ao momento e é quase o dobro do maior das soluções anteriores. Também $Z_{4}$ e $Z_{5}$ estão próximos dos máximos conhecidos. Esta solução considera a abertura das estações $F_{2}$ e $F_{4}$. Em $F_{4}$ são processadas 31085 unidades (valor de $\mathrm{Z}_{4}$ ) das quais 24275 (valor de $Z_{3}$ ) passam na ligação $W_{2}-F_{4}$.

Note-se que não houve qualquer normalização prévia das funções objectivo e, como estas têm escalas diferentes, houve um "privilégio" de $Z_{2}$, em detrimento das outras, visto que é $Z_{2}$ a
8662.5, 2597166). Obteve-se a solução 6 ao fim de um tempo de cálculo de 1.15 seg (computador Pentium II, 350MHz). função objectivo com maior ordem de grandeza de valores.

A fig. 6 mostra gráficos de barras para as 6 soluções calculadas. Esta figura, assim como as seguintes, são cópias de janelas do sistema onde a letra ' $F$ ' designa 'Função objectivo'. O sistema usa a mesma cor (tom de cinzento) para soluções com partes inteiras iguais que, neste problema, são aquelas que consideram a abertura das mesmas estações de tratamento. As opções de visualização disponíveis nesta janela são: hll-gráficos de barras; $\underline{\underline{X}}$ - gráficos de linhas; $\underbrace{-}_{-}$pontos no espaço dos critérios (apenas disponível para 2 e 3 funções objectivo); 넨 
disponível para os gráficos de barras e que permite (através de uma caixa de diálogo) escolher a opção de ordenação: por ordem crescente ou decrescente do índice da solução (como na fig. 6) ou pelos valores de uma das funções objectivo.

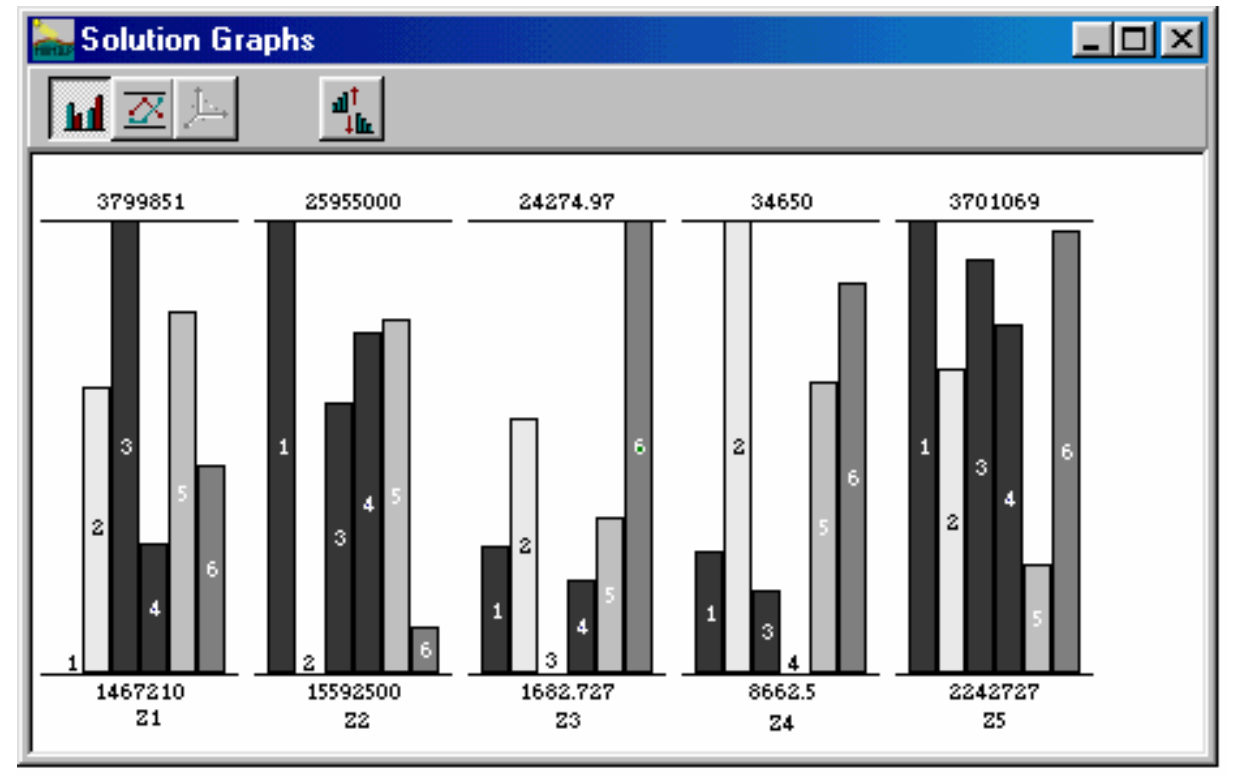

Fig. 6 - Gráficos de barras para as primeiras 6 soluções.

Sempre que se calcula uma solução, ela é apresentada ao utilizador na janela principal do sistema (figuras 7, 8 e seguintes). Esta janela inclui gráficos de barras para a(s) última(s) solução(ões) calculada(s), informação numérica e um painel com as principais opções. As opções dependem do tipo de cálculo efectuado (com pontos de referência ou pesos). Para um melhor entendimento da forma como o AD interage com o sistema na pesquisa que se segue, o diagrama seguinte faz uma breve descrição das opções disponíveis na abordagem baseada em pontos de referência. Estas opções estão divididas em 2 separadores do painel: 'Standard' e 'View Options'.

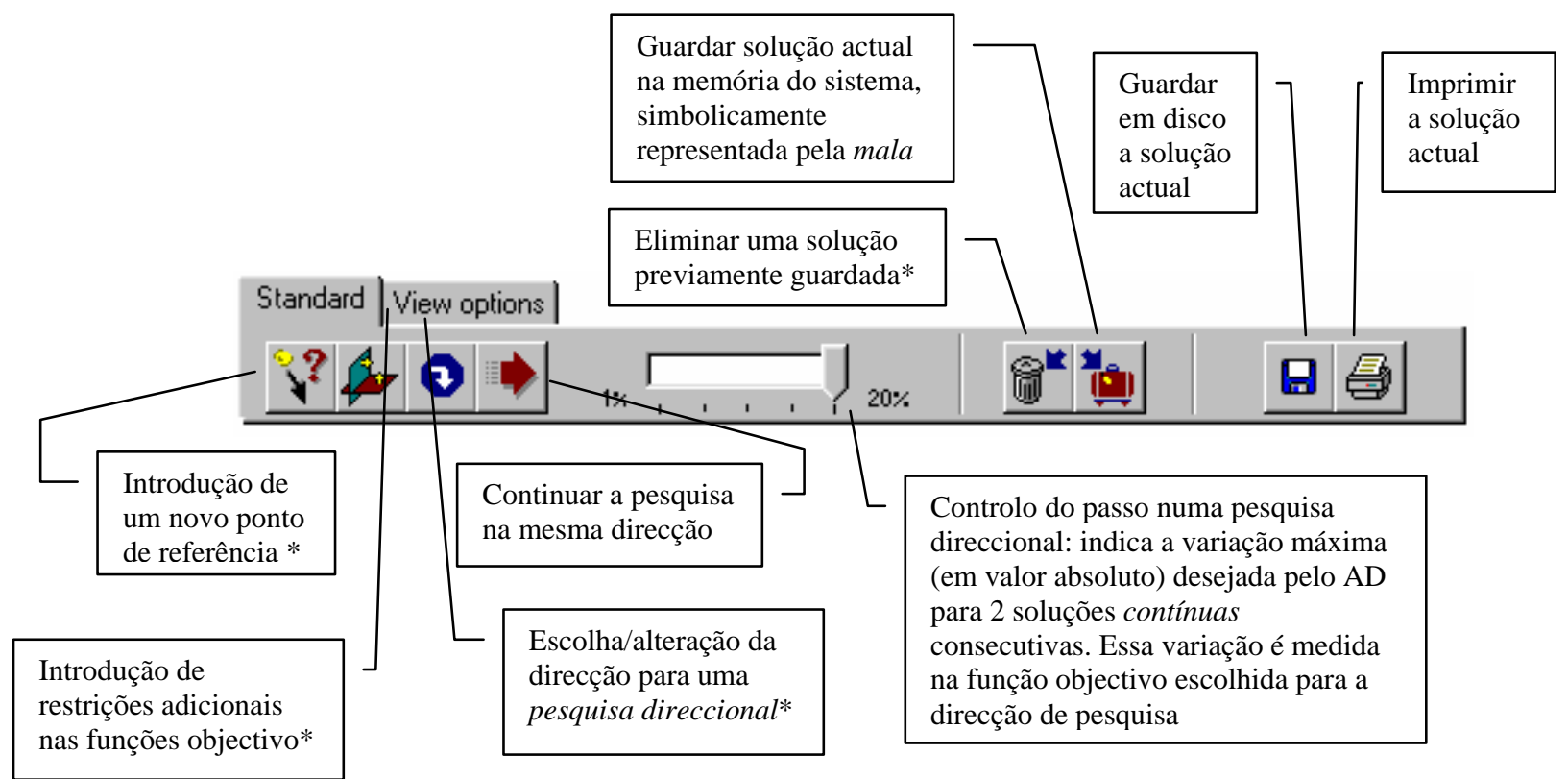

(*) Estas opções implicam a entrada de parâmetros através de caixas de diálogo 


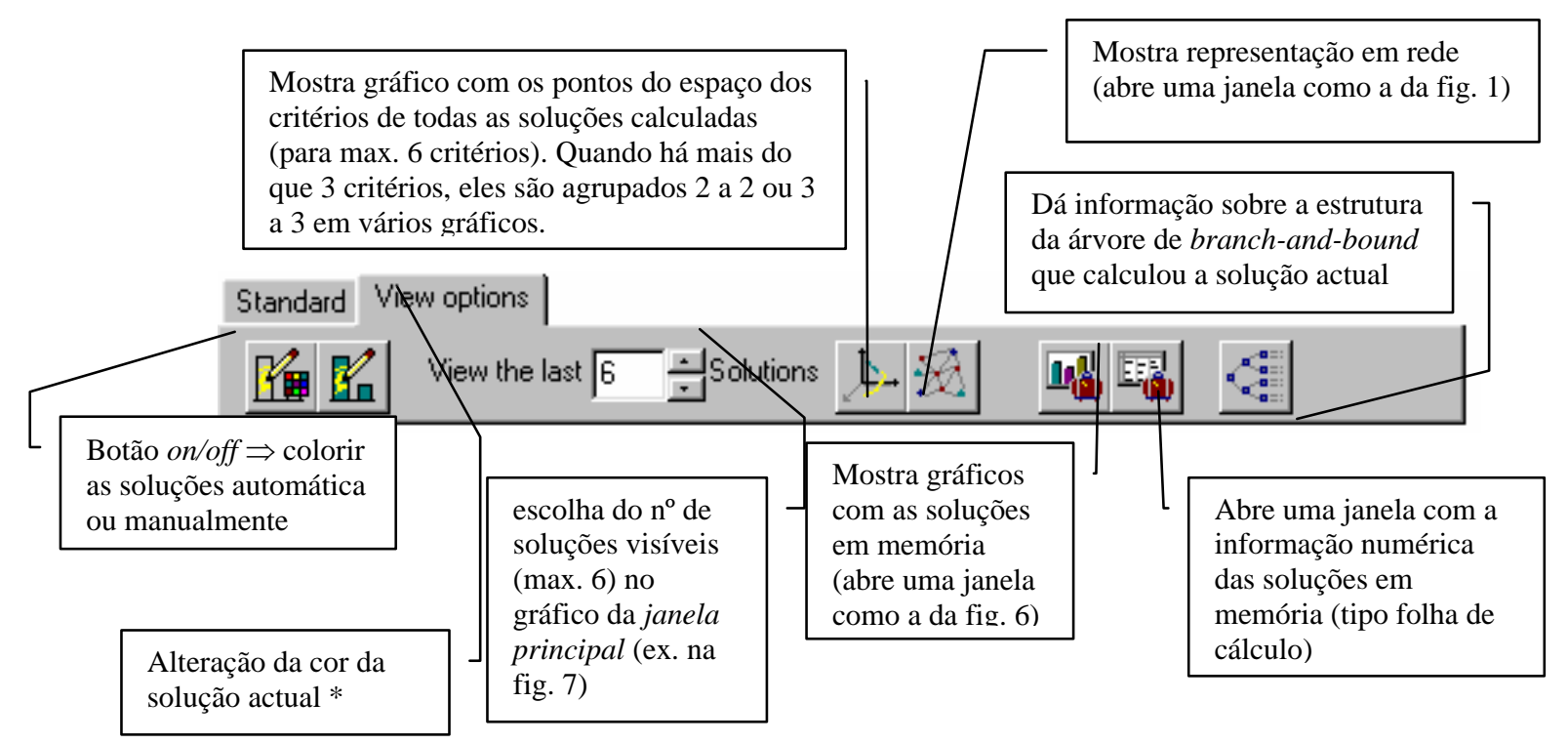

Continuando com o estudo do problema, decidiu-se, então, fazer uma pesquisa direccional a partir da última solução calculada (solução 6) escolhendo-se a $3^{\mathrm{a}}$ função objectivo para melhorar dado que é a mais sacrificada nesta solução. Esta decisão foi operacionalizada através do botão 3 do painel, que chama uma caixa de diálogo para selecção da função objectivo que o AD pretende melhorar.

Tal como foi descrito na secção 1 , quando é escolhida uma pesquisa direccional, o algoritmo actualiza automaticamente o ponto de referência $\underline{z}^{+}$ e determina a solução eficiente que minimiza a distância de Tchebycheff ao novo $\underline{z}^{+}$. O ponto de referência é modificado através da diminuição da $3^{\text {a }}$ componente (porque $Z_{3}$ é a minimizar) mantendo todas as outras componentes iguais (que actualmente são as componentes do ponto ideal).

Esta pesquisa direccional começa por determinar soluções em que $Z_{1}, Z_{2}$ e $Z_{5}$ aumentam e $Z_{3}$ e $Z_{4}$ diminuem. As primeiras soluções (primeiras iterações) são contínuas (as variáveis inteiras têm os mesmos valores): consideram a abertura das mesmas estações $\left(\begin{array}{llll}F_{2} & \text { e } & F_{4}\end{array}\right)$ e apresentam valores próximos para as funções objectivo.
O sistema calcula uma nova solução ao longo da mesma direcção sempre que é premido o botão

A dada altura (6 $6^{\text {a }}$ iteração/solução), há alteração das estações abertas que passam a ser $F_{1}, F_{2}$ e $F_{4}$ mas as tendências de variação das funções objectivo mantêmse (ver fig. 7).

Estamos perante a solução $\underline{Z}=(2573156$, 16698446, 19284, 30430, 3703112 ).

A ferramenta de pesquisa aqui utilizada evidencia que grandes "saltos" ao nível do ponto de referência $\underline{z}^{+}$nem sempre correspondem a variações bruscas nos valores das funções objectivo. Apesar de o AD se poder alhear, se assim o desejar, das variações automáticas de $\underline{\mathrm{z}}^{+}$, uma análise técnica deste processo permite também aumentar o conhecimento acerca do problema. O processo de análise de sensibilidade tenta sempre dar "passos curtos" de modo a que haja um varrimento total ao longo da direcção de pesquisa. Mas, por vezes é necessária uma grande variação do ponto de referência para "escapar" da solução anterior, o que não implica, necessariamente, grandes variações nas funções objectivo. Foi o que aconteceu na $1^{\text {a }}$ iteração desta pesquisa em que a $3^{\text {a }}$ componente de $\underline{\mathrm{z}}^{+}$(isto é, $\mathrm{z}_{3}^{+}$) baixou logo de 1682.7 para -1046281 (variação 
de $\left.-62 \times 10^{3} \%\right)$. As variações seguintes de $z_{3}^{+}$foram de $-9 \times 10^{-5} \%$ a $-2.2 \%$ por iteração. As variações dos valores das funções objectivo podem ser avaliadas pelos gráficos da fig. 7 (esta é a janela principal do sistema).

Nesta pesquisa calcularam-se 6 soluções em apenas 0.81 seg que representa $70 \%$ do tempo de cálculo da solução de partida. O tempo despendido em cada solução eficiente variou entre 0.06 seg e 0.27 seg. A fig. 7 mostra o tempo relativo à última solução (0.16 seg). Estes tempos incluem os da fase de análise de sensibilidade e os da actualização da árvore de branch-and-bound que determina cada solução.

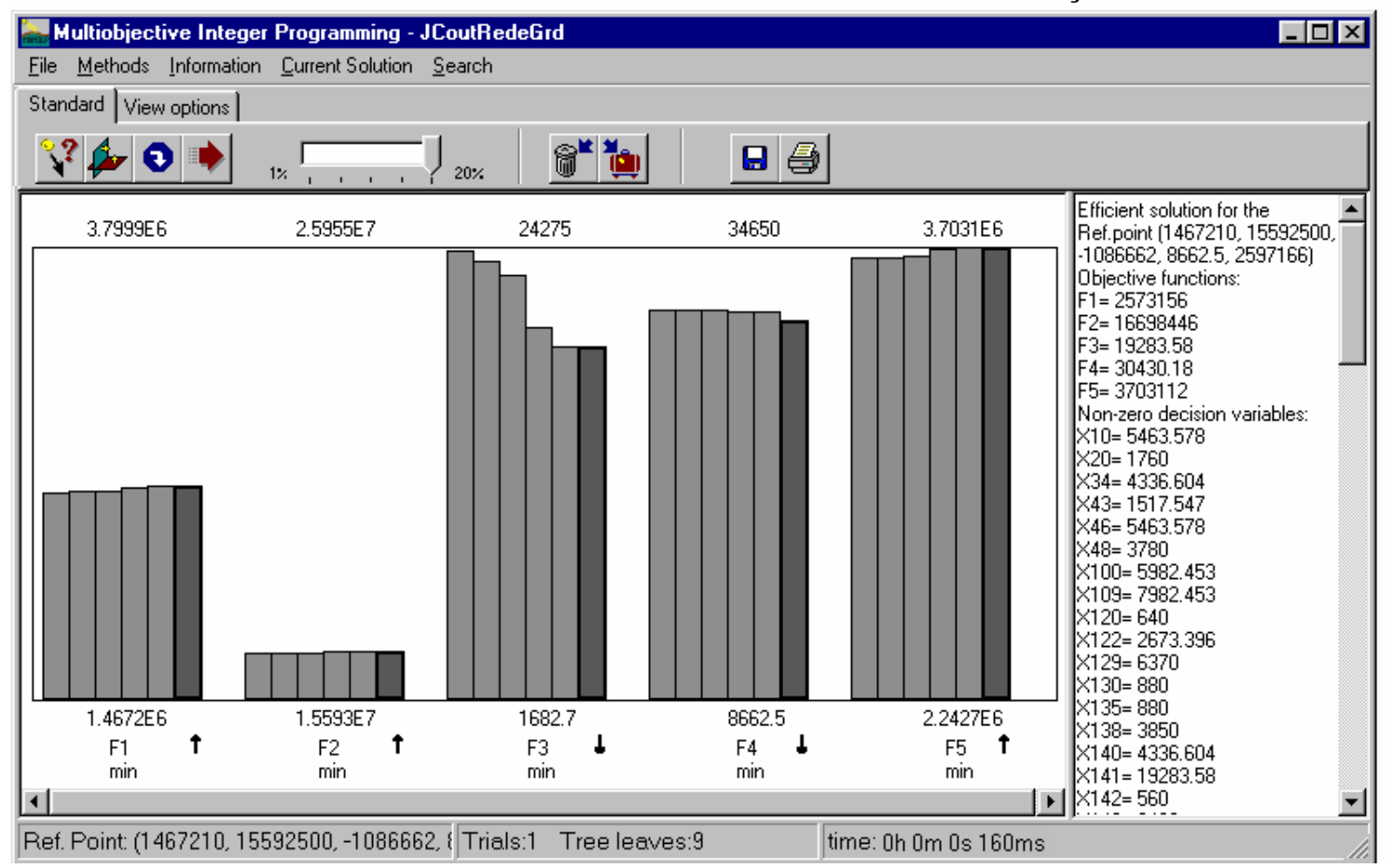

Fig. 7 - Primeira pesquisa direccional (diminuição da $3^{a}$ função objectivo).

Como o custo $\left(Z_{5}\right)$ das soluções obtidas é muito elevado, optou-se por alterar a direcção de pesquisa no sentido da diminuição do custo. Como consequência, inverteu-se inicialmente o sentido de variação de $\mathrm{Z}_{3}$ que começou a aumentar, retomando a situação de abertura das estações $F_{2}$ e $F_{4}$. Passadas algumas soluções $\left(6^{\mathrm{a}}\right.$ iteração nesta direcção), alterou-se a tendência de variação de $Z_{3}$ que diminui bruscamente. Simultaneamente, $Z_{5}$ diminui também bastante e $Z_{4}$ diminui ligeiramente apenas $Z_{1}$ e $Z_{2}$ aumentam ligeiramente (fig. 8). Mantém-se a situação de $F_{2}$ e $F_{4}$ abertas. Decidiu-se guardar esta solução - solução 7.

Nesta pesquisa direccional, a maior variação do ponto de referência ocorreu na última iteração onde $\mathrm{z}_{5}^{+}$baixou de 2458002 para 2175695 (variação de $11.5 \%)$.

\begin{tabular}{cccccc}
\hline & $\mathrm{Z}_{1}(\min )$ & $\mathrm{Z}_{2}(\min )$ & $\mathrm{Z}_{3}(\min )$ & $\mathrm{Z}_{4}(\min )$ & $\mathrm{Z}_{5}(\min )$ \\
\hline Solução 7 & 2661805 & 16787095 & 16837 & 30668 & 3370291 \\
\hline
\end{tabular}




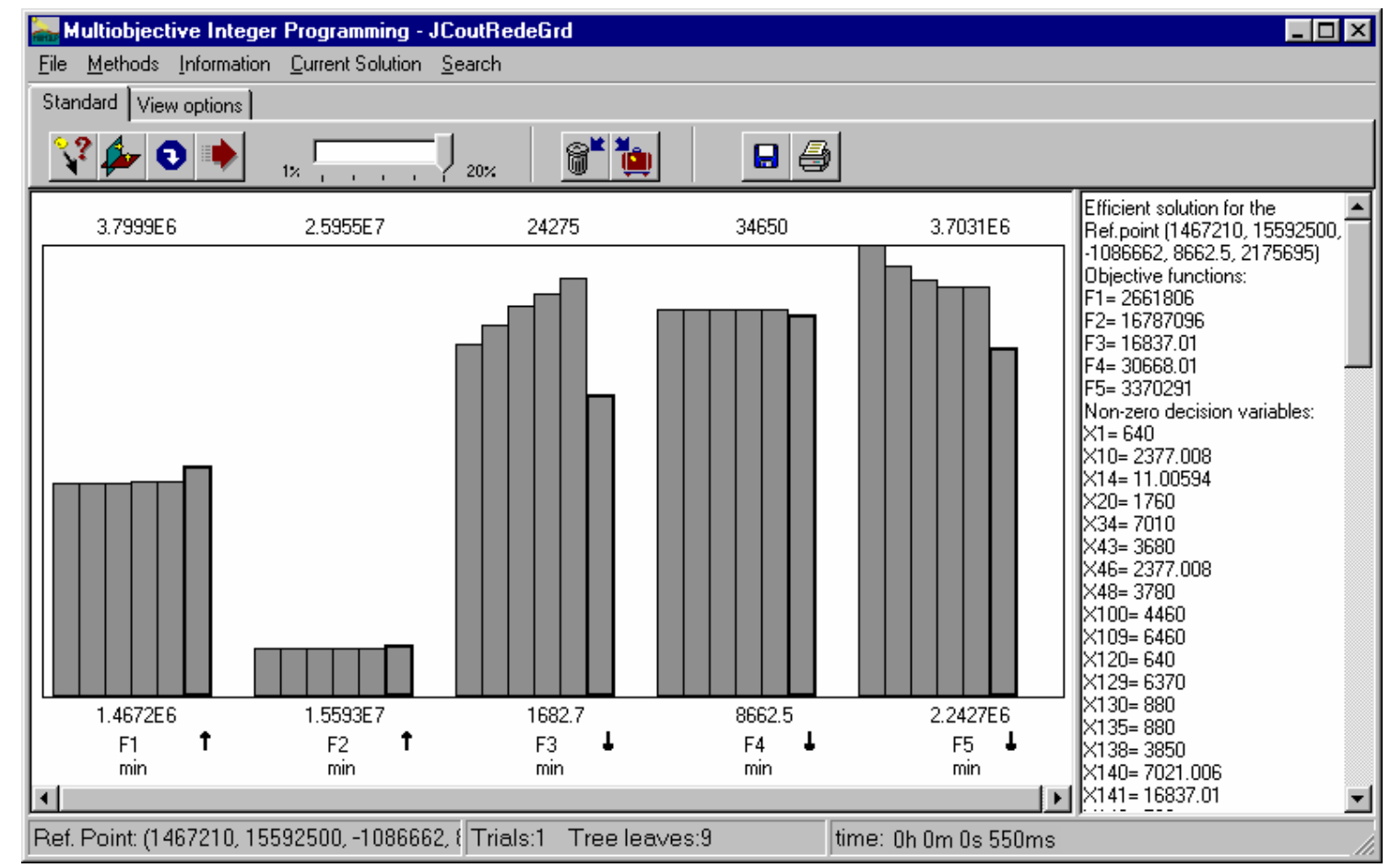

Fig. 8 - Segunda pesquisa direccional (diminuição da $5^{\text {a }}$ função objectivo).

Continuando a pesquisa segundo a mesma direcção, $Z_{3}$ diminui logo para 14460 e $Z_{5}$ para 3337144 . Mantêm-se as outras tendências de variação e durante algumas iterações verificam-se variações muito ligeiras: $\mathrm{Z}_{1}$ e $\mathrm{Z}_{2}$ aumentam, $\mathrm{Z}_{4}$ e $\mathrm{Z}_{5}$ diminuem; $Z_{3}$ mantém-se inicialmente a 14460 (5 iterações) descendo depois a 13820 onde se mantém durante 5 iterações. Na iteração seguinte, há um "salto abrupto" para uma solução com valores extremos em alguns dos critérios, semelhante à solução 2, onde se considera a abertura de apenas a estação $F_{4}$. A fig. 9 mostra esta solução e as 5 anteriores. Esta solução é provocada por uma variação de apenas $-0.5 \%$ em $\mathrm{z}_{5}^{+}$ relativamente ao da iteração anterior. $\mathrm{Z}_{4}$ atinge o máximo (conhecido até ao momento) e $Z_{2}$ o mínimo. Esta solução só difere da solução 2 nos valores de $Z_{1}$ (ligeiramente maior) e $Z_{5}$ (ligeiramente menor). Foi abandonada esta direcção de pesquisa.

Uma pesquisa direccional procura soluções não dominadas próximas, em que o "passo" máximo para as soluções contínuas é controlado pelo utilizador. No caso de um problema inteiro-misto, como é o caso, há troços de soluções contínuas, com valores próximos entre si, e há também descontinuidades quando se altera a parte inteira das soluções. As pesquisas direccionais efectuadas (a $1^{\mathrm{a}}$ no sentido da diminuição da maior exposição individual durante o transporte, $Z_{3}$, e a $2^{a}$ no sentido da diminuição do custo, $Z_{5}$ ) mostram alguns aspectos interessantes da geometria do problema: a existência de descontinuidades com muito pouco impacto nos valores das funções objectivo - fig. 7 - e a existência de outras descontinuidades com variações abruptas nos valores das funções objectivo - fig. 9. Para passar de um troço ao outro, basta por vezes um "toque" muito ligeiro no ponto de referência. Mas, outras vezes é necessária uma grande variação do ponto de referência. Este processo de alteração é automático. Assim, as pesquisas direccionais dão-nos uma percepção da geometria do problema que dificilmente seria obtida utilizando outro tipo de ferramenta de pesquisa. 


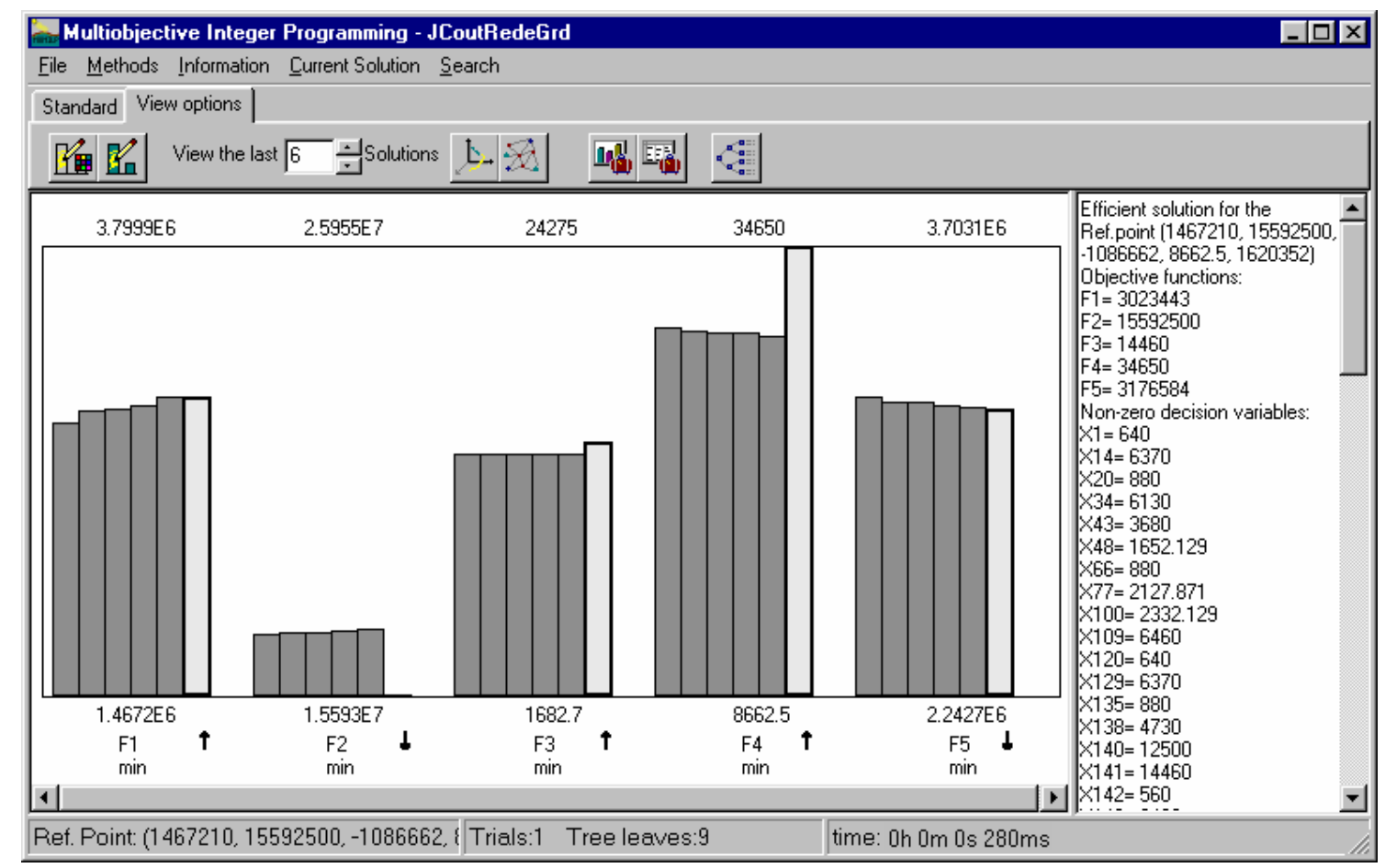

Fig. 9 - Continuação da pesquisa direccional anterior (diminuição da $5^{a}$ função objectivo).

Tendo em atenção os valores da solução 7 (última solução guardada) e as tendências de variação verificadas na pesquisa anterior, foi estipulado 0 seguinte ponto de referência: $\underline{\mathrm{z}}^{+}=\left(2 \times 10^{6}\right.$,
$20 \times 10^{6}, 10000,15000,3 \times 10^{6}$ ). A solução obtida - solução 8 - é relativamente equilibrada. Comparando-a com a solução imediatamente anterior, é melhor em todas as funções objectivo excepto $\mathrm{Z}_{2}$ (fig. 10) Considera a abertura das estações $F_{2}$ e $F_{4}$.

\begin{tabular}{cccccc}
\hline & $Z_{1}(\min )$ & $Z_{2}(\min )$ & $Z_{3}(\min )$ & $Z_{4}(\min )$ & $Z_{5}(\min )$ \\
\hline Solução 8 & 2028630 & 20028630 & 13053 & 19863 & 3028630 \\
\hline
\end{tabular}

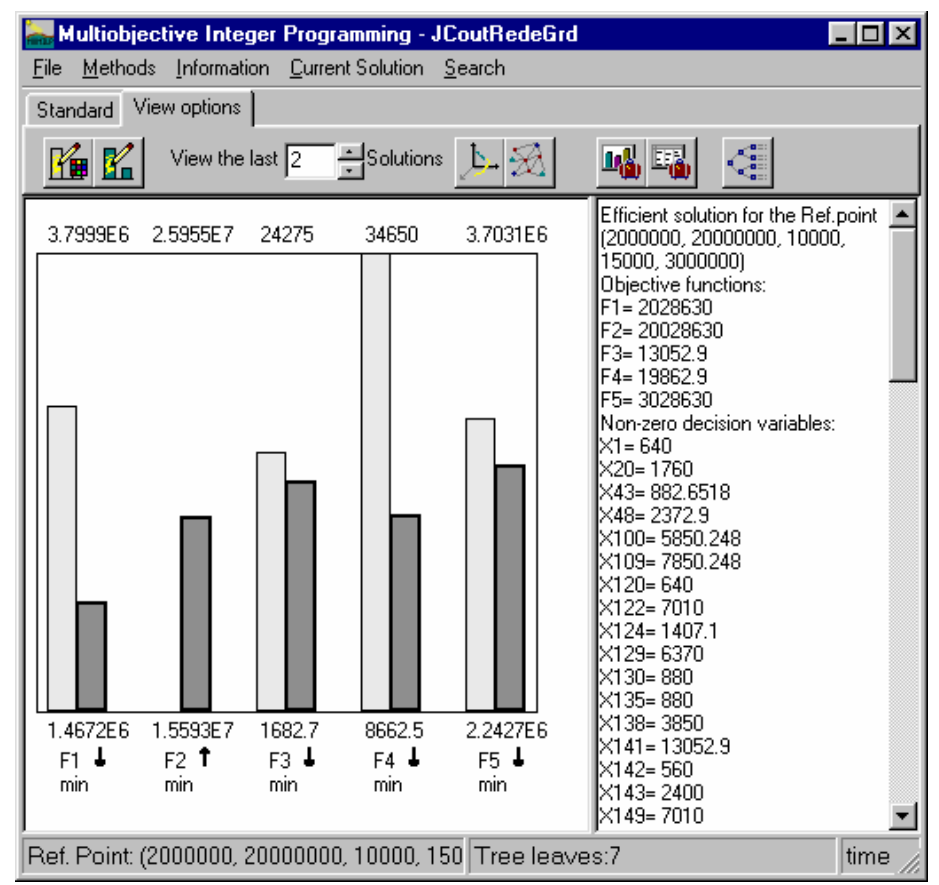

Fig. 10 - Solução 8 (mais escura) e a solução anterior. 
Partindo desta solução, procedeu-se a uma nova pesquisa direccional no sentido de tentar melhorar um pouco $Z_{2}$. As soluções obtidas sacrificam todas as outras funções objectivo para melhorar $Z_{2}$. Com $Z_{2}=18944650$ (4 ${ }^{a}$ solução desta pesquisa), resolveu-se impor a limitação adicional $\mathrm{Z}_{2} \leq 19 \times 10^{6}$ (através da opção (4)) e escolher novamente $Z_{3}$ para melhorar. $Z_{2}$ atinge exactamente os $19 \times 10^{6}, Z_{3}$ diminui e $Z_{1}$ e $Z_{5}$ aumentam ( $\mathrm{Z}_{4}$ tem também um ligeiro aumento). Passadas algumas soluções com variações muito pequenas, é encontrada uma outra solução que considera a abertura das estações $F_{1}, F_{2}$ e $F_{4}$ e que diminui o valor de $Z_{4}$ - solução 9 .

\begin{tabular}{cccccc}
\hline & $\mathrm{Z}_{1}(\min )$ & $\mathrm{Z}_{2}(\min )$ & $\mathrm{Z}_{3}(\min )$ & $\mathrm{Z}_{4}(\min )$ & $\mathrm{Z}_{5}(\min )$ \\
\hline Solução 9 & 2253931 & 19000000 & 12321 & 21509 & 3253931 \\
\hline
\end{tabular}

Continuando a pesquisa na mesma direcção, verifica-se que $Z_{2}$ se mantém, $Z_{1}$ e $Z_{5}$ aumentam e $Z_{3}$ e $Z_{4}$ diminuem. Em virtude do custo total estar a tornar-se bastante elevado, resolveu-se escolher $Z_{5}$ para melhorar adicionando-se a limitação
$\mathrm{Z}_{3} \leq 9000$ para obrigar $\mathrm{Z}_{3}$ a diminuir também. O ponto de referência actual é $\left(2 \times 10^{6}, 18761566,-334898.3,15000\right.$, $3 \times 10^{6}$ ). A solução eficiente mais próxima deste ponto de referência que satisfaz as duas limitações adicionais é a solução 10.

\begin{tabular}{cccccc}
\hline & $\mathrm{Z}_{1}(\min )$ & $\mathrm{Z}_{2}(\min )$ & $\mathrm{Z}_{3}(\min )$ & $\mathrm{Z}_{4}(\min )$ & $\mathrm{Z}_{5}(\min )$ \\
\hline Solução 10 & 2346793 & 19000000 & 9000 & 21892 & 3346793 \\
\hline
\end{tabular}

Prosseguindo no sentido de melhorar $Z_{5}$, obtêm-se inicialmente soluções em que $\mathrm{Z}_{2}$ e $\mathrm{Z}_{3}$ mantêm os valores das limitações, $\mathrm{Z}_{4}$ mantém-se a $20225, \mathrm{Z}_{1}$ aumenta e $\mathrm{Z}_{5}$ diminui. Passadas algumas soluções (7 iterações), há um aumento significativo em $Z_{4}$ para 23291 sem grandes contrapartidas nas outras funções objectivo. A estação $F_{1}$ já não está aberta, mas apenas $F_{2}$ e $F_{4}$. É uma solução que nos pareceu desinteressante (penúltima solução na fig. 11).

Decidiu-se, então, impor mais uma limitação adicional, desta vez em $\mathrm{Z}_{4}$ : $\mathrm{Z}_{4} \leq 20000$. A solução eficiente mais próxima do ponto de referência actual, $\left(2 \times 10^{6}, 18761566,-334898.3,15000\right.$, $2767193)$, que satisfaz as três limitações adicionais é a solução 11 (fig.11).

\begin{tabular}{cccccc}
\hline & $\mathrm{Z}_{1}(\min )$ & $\mathrm{Z}_{2}(\min )$ & $\mathrm{Z}_{3}(\min )$ & $\mathrm{Z}_{4}(\min )$ & $\mathrm{Z}_{5}(\min )$ \\
\hline Solução 11 & 2415817 & 19000000 & 9000 & 20000 & 3183010 \\
\hline
\end{tabular}




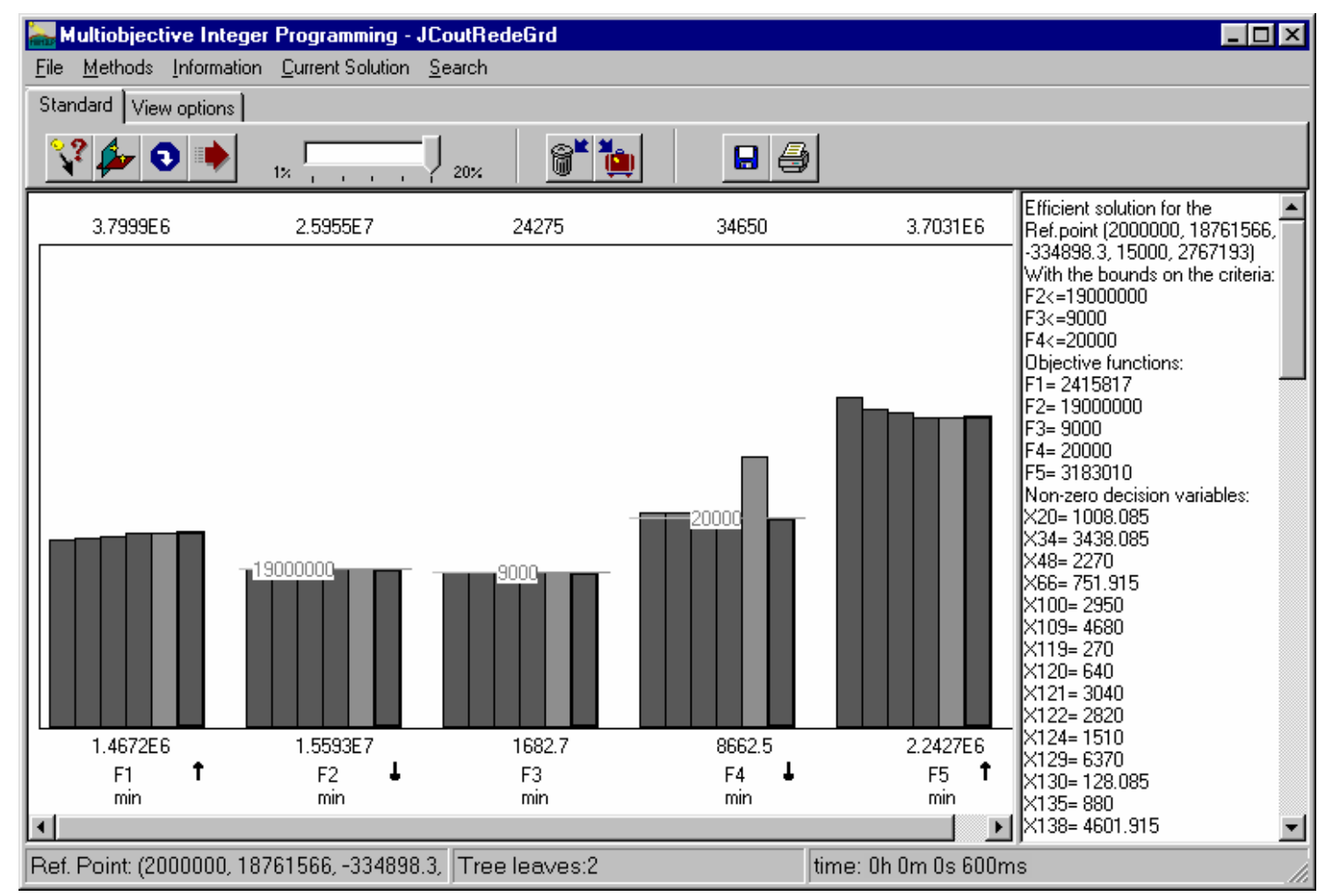

Fig. 11 - Solução 11 (barra à direita, em cada coluna) e pesquisa que antecedeu o cálculo desta solução.

Esta solução parece-nos apresentar um compromisso satisfatório entre os vários critérios.

A solução 11 tem as seguintes características. São abertas as estações de tratamento $F_{1}, F_{2}$ e $F_{4}$ que processam, respectivamente, 3950, 10700 e 20000 unidades. A quantidade máxima processada é, assim, de 20000, indicador do maior risco individual em estações de tratamento $\left(\mathrm{Z}_{4}\right)$. A maior exposição ao resíduo durante o transporte $\left(Z_{3}\right)$ é 9000 dada pela ligação $W_{2}-F_{4}$. O local da estação $F_{3}$ funciona como ponto de passagem de 1008 unidades. A rede correspondente a esta solução está representada na fig. 12 . Observa-se, nesta rede, que é utilizado o percurso $T_{11}-F_{3}-$ $W_{11}$ quando existe uma ligação directa $T_{11}-W_{11}$. É uma situação contra-intuitiva que, tal como outras já observadas anteriormente (por exemplo nas soluções 1 e 4), relaciona-se com o compromisso risco total do transporte $\left(\mathrm{Z}_{1}\right) /$ custo total $\left(Z_{5}\right)$. O custo de transporte em $T_{11}-F_{3}-$ $W_{11}$ é $50.56(=25.06+25.5)$ por unidade de resíduo enquanto que em $T_{11}-W_{11}$ é 7.62. Por outro lado, a população de $T_{11}-$ $F_{3}-W_{11}$ sujeita a risco totaliza 14 enquanto que em $T_{11}-W_{11}$ é 90 . 


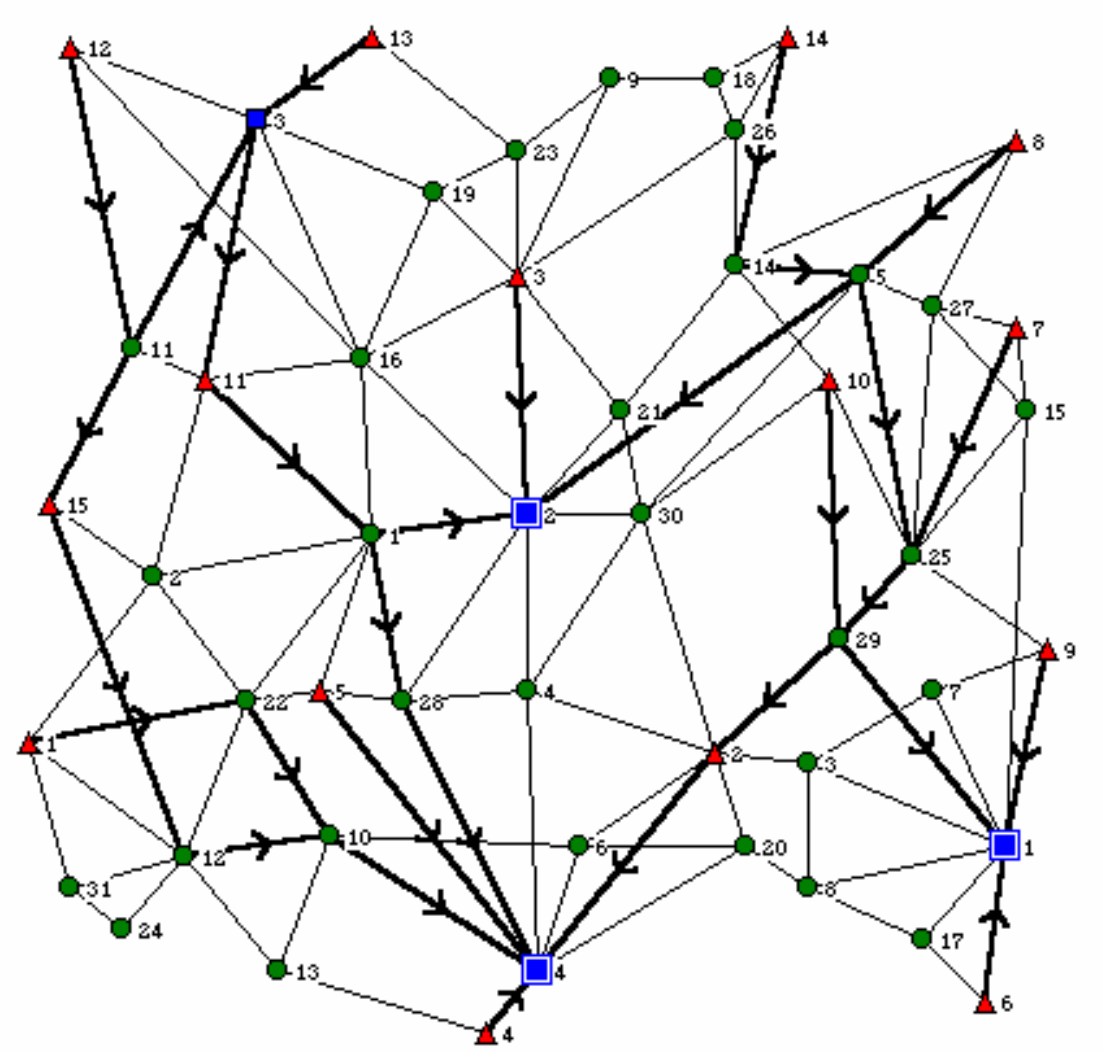

$\square$ rac $\square$ aberta

O $\mathrm{Tr}$

A WASTR

Fig. 12 - Rede da solução 11.

As fig. 13 e 14 resumem o estudo efectuado para este problema mostrando gráficos de barras e os valores das 11 soluções eficientes analisadas e guardadas.

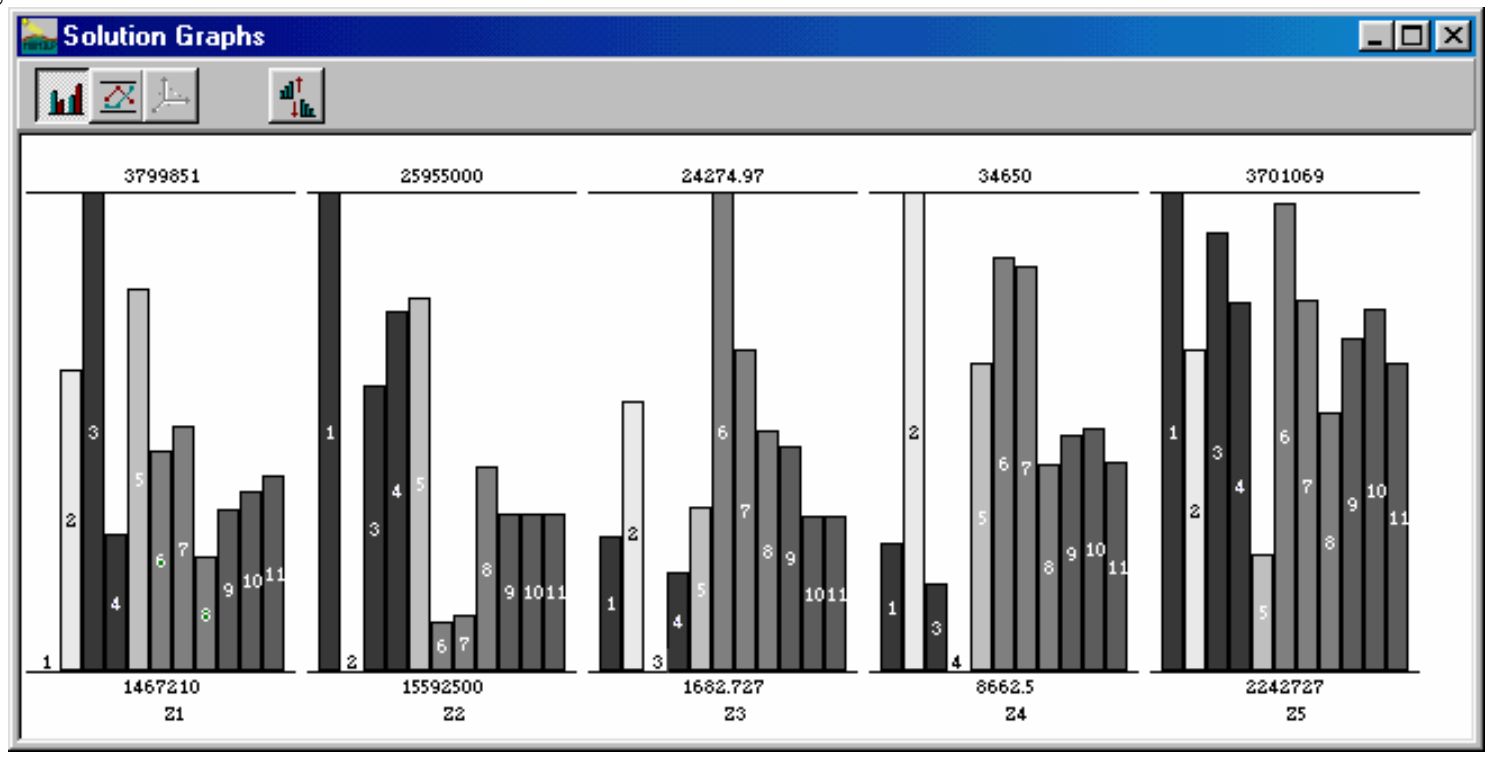

Fig. 13 - Gráficos de barras das 11 soluções eficientes guardadas. 


\begin{tabular}{|c|c|c|c|c|c|c|}
\hline & $\begin{array}{c}\text { Estações } \\
\text { abertas }\end{array}$ & $\mathrm{Z}_{1}(\mathrm{~min})$ & $\mathrm{Z}_{2}$ (min) & $\mathrm{Z}_{3}(\mathrm{~min})$ & $\mathrm{Z}_{4}(\mathrm{~min})$ & $\mathrm{Z}_{5}(\mathrm{~min})$ \\
\hline Solução 1 & $1,2,3,4$ & 1467210 & 25955000 & 8040 & 15630 & 3701069 \\
\hline Solução 2 & 4 & 2939590 & 15592500 & 14460 & 34650 & 3223059 \\
\hline Solução 3 & $1,2,3,4$ & 3799851 & 21770318 & 1682.7 & 13462 & 3579522 \\
\hline Solução 4 & $1,2,3,4$ & 2137958 & 23388750 & 6370 & 8662.5 & 3367100 \\
\hline Solução 5 & 1,2 & 3324450 & 23677500 & 9410 & 25410 & 2597166 \\
\hline Solução 6 & 2,4 & 2536719 & 16662009 & 24275 & 31085 & 3666675 \\
\hline Solução 7 & 2,4 & 2661805 & 16787095 & 16837 & 30668 & 3370291 \\
\hline Solução 8 & 2,4 & 2028630 & 20028630 & 13053 & 19863 & 3028630 \\
\hline Solução 9 & $1,2,4$ & 2253931 & 19000000 & 12321 & 21509 & 3253931 \\
\hline Solução 10 & $1,2,4$ & 2346793 & 19000000 & 9000 & 21892 & 3346793 \\
\hline Solução 11 & $1,2,4$ & 2415817 & 19000000 & 9000 & 20000 & 3183010 \\
\hline
\end{tabular}

Fig. 14 - Tabela de valores das 11 soluções eficientes analisadas.

Fixando as funções objectivo de equidade de risco $\left(Z_{3}\right.$ e $\left.Z_{4}\right)$ em 9000 e 20000 , respectivamente, fizemos ainda uma pesquisa local na vizinhança da solução 11 considerando apenas os critérios $Z_{1}$, $Z_{2}$ e $Z_{5}$. A fig. 15 mostra os pontos no espaço dos critérios referentes às soluções pesquisadas: a solução de partida (solução 11) está representada por A; primeiro analisaram-se soluções que melhorassem $Z_{5}$ - até à solução $\mathrm{B} \equiv(2882798, \quad 19466981, \quad 2989890)-$ e, em seguida, soluções que melhorassem $\mathrm{Z}_{1}$ - até à solução $\mathrm{C} \equiv(2274689$, $19606441,3129351)$. Note-se que o gráfico da fig. 15 utiliza escalas iguais às dos gráficos anteriores o que, apesar de dificultar a visualização, permite situar melhor no espaço esta pesquisa local. A fig. 16 esclarece a evolução dos valores nos 3 critérios através de gráficos de barras. Todas esta soluções consideram a abertura das mesmas estações de tratamento de resíduo, $F_{1}, F_{2}$ e $F_{4}$.

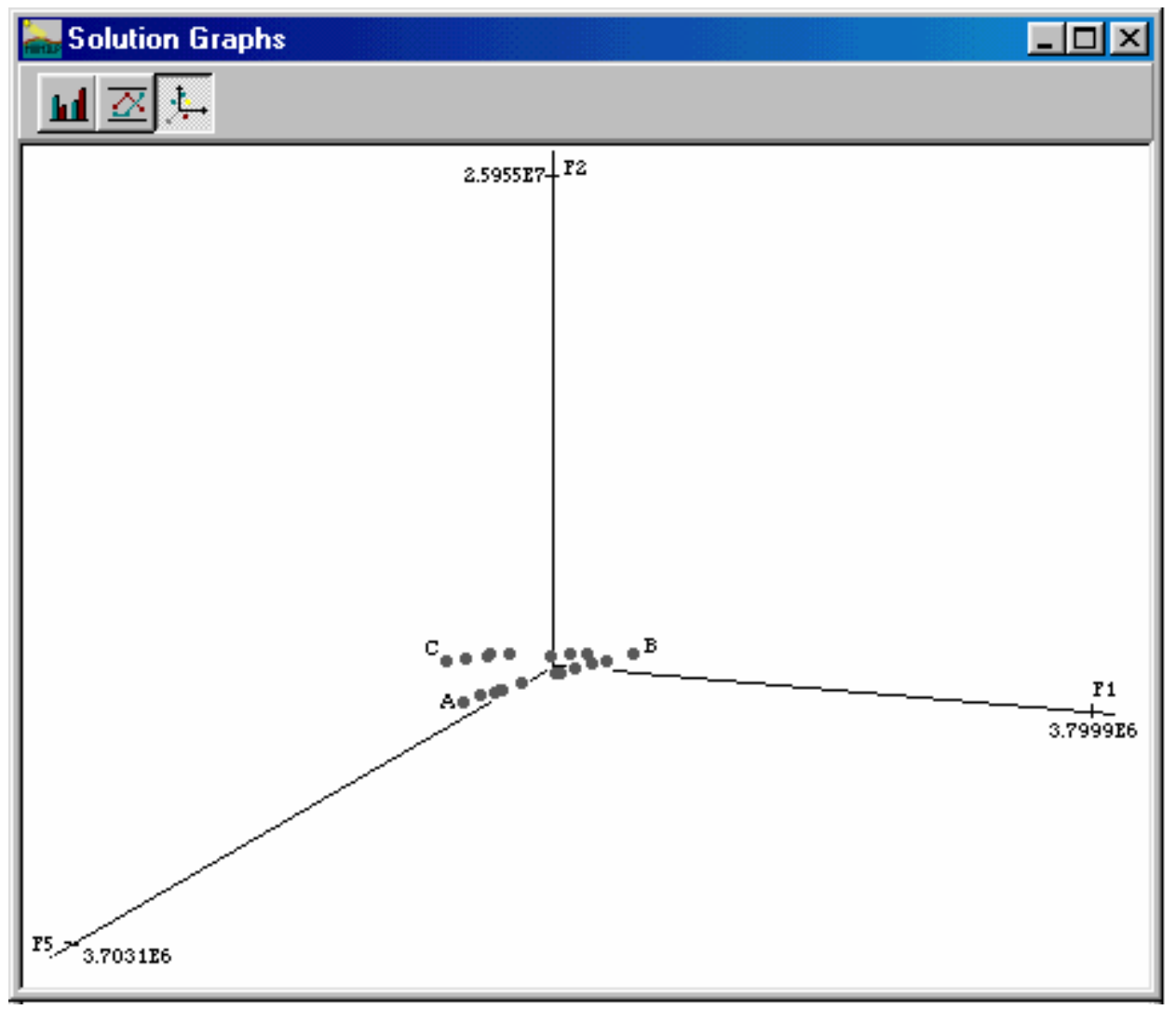

Fig. 15 - Espaço dos critérios numa pesquisa local com $Z_{3}$ e $Z_{4}$ fixas. 


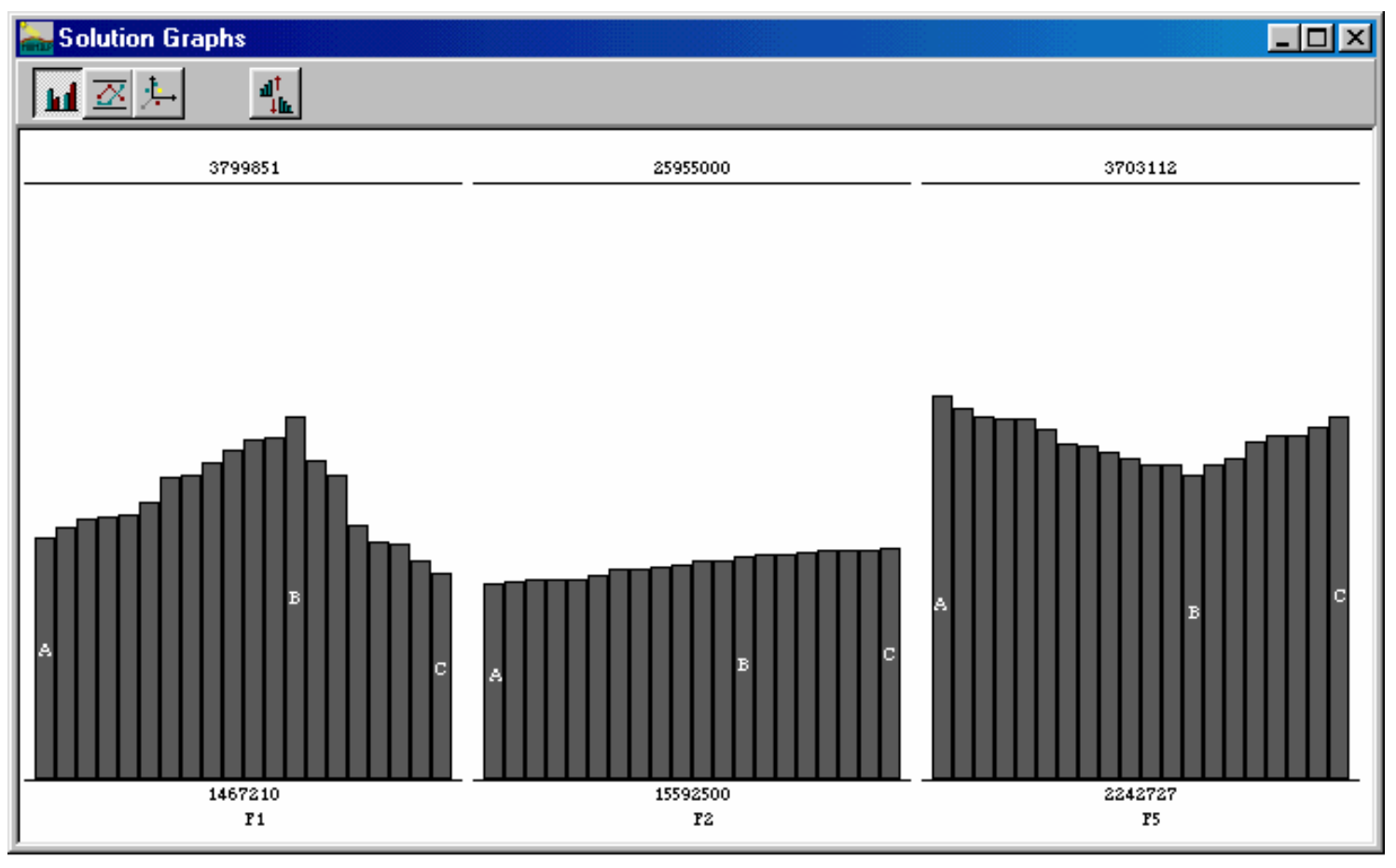

Fig. 16 - Gráficos de barras duma pesquisa local com $\mathrm{Z}_{3}$ e $\mathrm{Z}_{4}$ fixos.

\section{CONCLUSÕES}

Neste trabalho descrevemos a aplicação de uma abordagem interactiva baseada em pontos de referência a um problema multiobjectivo de localizaçãotransporte. Foram apresentados alguns resultados (parciais) ilustrativos do estudo efectuado para o problema. Deste estudo, ressaltaram as seguintes características do problema:

- As funções objectivo $Z_{2}, Z_{3}$ e $Z_{4}$, admitem várias soluções óptimas alternativas (eficientes e também fracamente eficientes) quando optimizadas individualmente. Assim, as soluções 2, 3 e 4 não são as únicas soluções eficientes em que se atinge o valor mínimo para a respectiva função objectivo.

- O valor máximo (pior) da tabela de "pay-off” para a função objectivo $\mathrm{Z}_{3}$ está muito aquém do máximo eficiente para este critério (veja-se, por ex., a solução 6), pelo que a percepção inicial da gama de valores eficientes dada pela tabela de "pay- off” é grosseira, pelo menos para este critério.

- As pesquisas direccionais evidenciam que há soluções eficientes com variações muito pequenas em 4 das 5 funções objectivo e uma variação significativa na restante (positiva ou negativa) - compare-se, por ex., a solução 11 com a anterior a esta. Apesar de estas soluções serem todas não dominadas, haverá certamente alguma(s) que é (são) claramente preferida(s) pelo AD em detrimento das outras.

- $\quad$ Na nossa opinião, na formulação do problema apresentada na secção 2 poderia incluir-se 0 grupo de restrições $\sum_{i} X_{j i} \leq \mathrm{M}, \forall j \in F$. Isto deve-se ao facto de os nós de estações de tratamento poderem também funcionar como nós de passagem e $\sum_{i} X_{j i}$ representa todo o resíduo que passa no nó $j \in F$ sem que seja lá processado. As soluções eficientes apresentadas na secção anterior não seriam afectadas por estas restrições porque o maior valor de resíduo transportado $(M)$ atravessa outros nós 
ou arcos. Contudo, existem outras soluções eficientes do problema obtidas durante o estudo onde estas restrições têm influência. A título de exemplo, o problema admite uma solução eficiente onde $M=9817$ mas no nó relativo à estação 2 (fechada) passam 10860 unidades que não são contabilizadas para $M$.

A abordagem interactiva usada neste trabalho assenta essencialmente numa forma de pesquisa direccional considerando, em geral, restrições adicionais nos valores das funções objectivo. A principal vantagem desta abordagem reside na rapidez de cálculo durante as pesquisas direccionais, o que se explica pelo facto de se aproveitar a informação do cálculo de uma solução para calcular a seguinte. Qualquer outro processo implica a resolução independente de um problema escalarizante de cada vez que se pretende determinar uma nova solução. Há ainda a salientar o facto da actualização do ponto de referência ser automática o que permite que o AD se possa demitir desta tarefa, com a garantia que e a solução encontrada será sempre diferente da anterior e melhor para um critério seleccionado.

Esta abordagem é substancialmente diferente da outra abordagem interactiva já experimentada por outros autores para o mesmo tipo de problema [3, 4]. Esta diferenciação torna difícil qualquer comparação de tácticas ou resultados. Julgamos, porém, que as duas abordagens podem ser consideradas complementares.

\section{REFERÊNCIAS}

[1] Alves, M. João e João Clímaco. An Interactive Reference Point Approach for Multiobjective Mixed-integer Programming using Branch-andbound. European Journal of Operational Research, vol. 124, $\mathrm{n}^{\circ} 3$, 478-494, 2000.

[2] Alves, M. João e João Clímaco. A note on a decision support system for

ENGEVISTA, v. 7, n. 1, p. 32-54, abril 2005 multiobjective integer and mixedinteger programming problems. European Journal of Operational Research, vol. 155, $\mathrm{n}^{\circ}$ 1, 258-265, 2004.

[3] Coutinho-Rodrigues, J., J. Current, J. Clímaco e S. Ratick. "An interactive spatial decision support system for multiobjective HAZMAT locationrouting problems". (a) Transportation Research Board, Record 1602, 101109, 1997. (b) Uma versão prévia foi publicada em WPS 95-39, Max M. Fisher College of Business, The Ohio State University, 1995.

[4] Coutinho-Rodrigues, J., J. Clímaco, J. Current e S. Ratick. "A guided tour to an interactive location-routing software package using an HAZMAT case”, Working Paper, 1997.

[5] Current, J. E S. Ratick. "A model to assess risk, equity and efficiency in facility location and transportation of hazardous materials". Location Science, vol. 3, n 3, 187-201, 1995. 